Adauto de Souza Spindola Junior

Análise do perfil de expressão de metaloproteinases

(MMPs) e seus inibidores, Timp e Reck, em modelo animal de Doença de Parkinson.

Dissertação apresentada ao Programa de PósGraduação Interunidades em Biotecnologia do Instituto de Ciências Biomédicas da Universidade de São Paulo, para obtenção do Título de Mestre em Biotecnologia.

São Paulo 
Adauto de Souza Spindola Junior

Análise do perfil de expressão de metaloproteinases

(MMPs) e seus inibidores, Timp e Reck, em modelo animal

de Doença de Parkinson.

Dissertação apresentada ao Programa de PósGraduação Interunidades em Biotecnologia do Instituto de Ciências Biomédicas da Universidade de São Paulo, para obtenção do Título de Mestre em Biotecnologia.

Área de concentração: Biotecnologia

Orientadora: Profa. Dra. Mari Cleide Sogayar

Versão original

São Paulo

2019 


\section{CATALOGAČ̃̃ NA PUBLICAÇ̃̃O (CIP) \\ Serviço de Biblioteca e informação Biomédica \\ do Instituto de Ciências Biomédicas da Universidade de Săo Paulo}

Ficha Catalográfica elaborada pelo(a) autor(a)

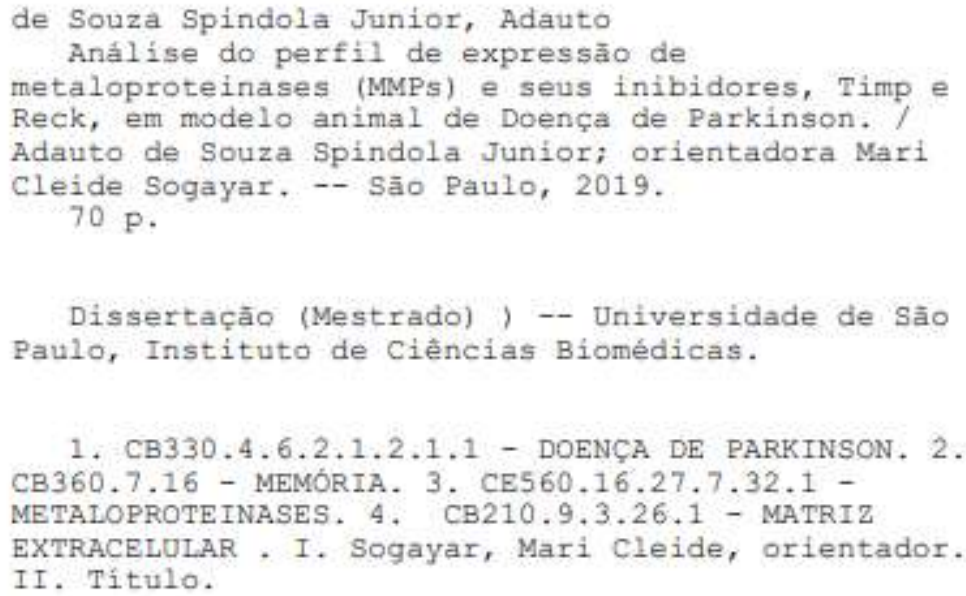

1. CB330.4,6.2.1.2.1.1 - DOENCA DE PARKINSON. 2. CB360.7.16 - MEMÓRIA. 3. CE560.16.27.7.32.1 METALOPROTEINASES. 4. CB210.9.3.26.1 - MATRIZ EXTRACELULAR. I. Sogayar, Mari Cleide, orientador. II. Titulo. 


\section{UNIVERSIDADE DE SÃO PAULO \\ Programa de Pós-Graduação Interunidades em Biotecnologia}

Universidade de São Paulo, Instituto Butantan, Instituto de Pesquisas Tecnológicas

Candidato(a): Adauto de Souza Spindola Junior

Titulo da Dissertação: Análise do perfil de expressão de metaloproteinases (MMPs) e seus inibidores, Timp e Reck, em modelo animal de Doença de Parkinson.

Orientador: Profa. Dra. Mari Cleide Sogayar

A Comissão Julgadora dos trabalhos de Defesa da Dissertação de Mestrado, em sessão publica realizada a ............................., considerou o(a) candidato(a):

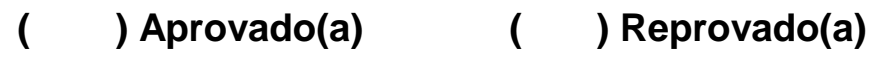

Examinador(a):

Assinatura:

Nome:

Instituição:

Examinador(a):

Assinatura:

Nome:

Instituição:

Examinador(a):

Assinatura:

Nome:

Instituição:

Presidente:

Assinatura:

Nome:

Instituição: 


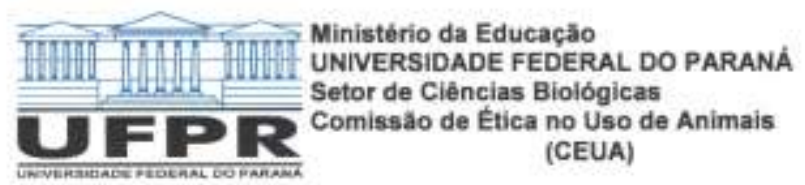

\section{CERTIFICADO}

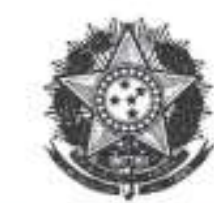

A Comissăo de Ética no Uso de Animais do Setor de Ciências Biológicas da Universidade Federal do Paraná (CEUA/BIO - UFPR), instituida pela Resoluçāo No $86 / 11$ do Conselho de Ensino Pesquisa e Extensăo (CEPE), de 22 de dezembro de 2011, CERTIFICA que os procedimentos utilizando animais no projeto de pesquisa abaixo especificado estăo de acordo com a Diretriz Brasileira para o Cuidado e a Utilizaçāo de Animais para fins Cientificos e Didáticos (DBCA) estabelecidas pelo Conselho Nacional de Controle de Experimentaçăo Animal (CONCEA) e com as normas internacionais para a experimentaçăo animal.

\section{STATEMENT}

The Ethics Committee for Animal Use from the Biological Sciences Section of the Federal University of Parana (CEUAVBIO - UFPR), established by the Resolution $\mathrm{N}^{\circ} 86 / 11$ of the Teaching Research and Extension Council (CEPE) on December $22^{\text {nd }}$ 2011, CERTIFIES that the procedures using animals in the research project specified below are in agreement with the Brazilian Guidelines for Care and Use of Animals for Scientific and Teaching purposes established by the National Council for Control of Animal Experimentation (CONCEA) and with the international guidelines for animal experimentation.

PROCESSOIPROCESS: $23075.049461 / 2014-16$

APROVADO/APPROVAL: 16/12/2014 - R.O. 10/2014

TíTULO/TITLE: Análise da interaçăo entre neurônios GABAérgicos REM-on/REMoff e a triade composta pelo núcleo pedúnculo-pontino, substância negra pras compacta e estriado na regulação do sono REM

AUTORESIAUTHORS: Marcelo de Meira Santos Lima, Adriano Targa Dias Santos

DEPARTAMENTO/DEPARTMENT: Fisiologia

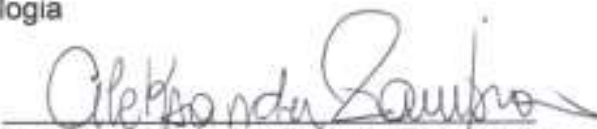

Prof. Dr. Aleksander Roberto Zampronio Coordenador da CEUA 
Aos meus queridos pais, Adauto de Souza Spindola e Maria de Fatima Vidal da Silva Spindola, e irmã, Patricia da Silva Spindola Parmejani, por todo amor, apoio e compreensão que me deram durante toda a vida e, especialmente nesses últimos 4 anos.

Ao meu amado sobrinho, Gabriel Spindola Parmejani, por me mostrar a forma mais sincera e pura de amor. 


\section{Agradecimentos}

Muitas pessoas participaram de alguma forma na elaboração deste trabalho, seja diretamente ou mesmo dando qualquer tipo de incentivo. Gostaria de citar todos aqui, mas minha memória com certeza irá me trair e pessoas importantes irão ficar de fora. De qualquer forma alguns agradecimentos devem ser feitos:

- À Profa. Mari Cleide Sogayar, por todo apoio e oportunidades de permitir que realizasse iniciação cientifica e mestrado sob sua orientação;

- À Dra. Marina Trombetta-Lima, pela supervisão e ensinamentos, dentro e fora do laboratório.

- À toda equipe da Universidade Federal do Paraná que trabalhou neste projeto e viabilizou os experimentos em animais.

- Aos meus amigos, que sempre estiveram dispostos a sair para comer, beber, ou simplesmente bater papo, tudo para me distrair e ajudar a não lembrar dos problemas.

- Um agradecimento especial para Thais Ribas, pela companhia durante o mestrado, pela companhia nos experimentos até altas horas da noite. Por ouvir minhas reclamações, meus desabafos e pelos conselhos dados.

- À CAPES pelo auxílio financeiro, disponibilizando bolsa de estudo durante dois anos do Mestrado, e a todas as Agências Financiadoras que disponibilizaram verbas para a realização deste projeto. 
"Eis o meu segredo: só se vê bem com o coração. O essencial é invisível aos olhos. Os homens esqueceram essa verdade, mas tu não a deves esquecer. Tu te tornas eternamente responsável por aquilo que cativas." 


\section{Lista de Abreviações}

Adam - A Disintegrin and Metalloprotease

AlF - Apoptosis Inducing Factor

ARC - Activity-Regulated Cytoskeleton-associated protein

BDNF - Brain-Derived Neurotrophic Factor

ECM - Extracellular Matrix

EEG - Electroencephalogram

HPLC - High performance liquid chromatography

Mmp - Matrix Metalloproteinase

MPTP - 1-Metil-4-fenil-1,2,3,6-tetrahidropiridina

NPC - Neural Progenitor Cells

NQO1 - DT-diaforase

PD - Parkinson Disease

PSD-95 - PostSynaptic Density protein 95

PSREM - Privação de Sono REM

Reck- REversion-inducing- Cysteine-rich protein with Kazal motifs

REM - rapid-eye- movement sleep

Sam68 - Src-Associated in Mitosis $68 \mathrm{KDa}$

$\mathrm{SN}$ - Substancia Nigra

SWS - Slow-Wave Sleep

Timps - Tissue Inhibitors of Metalloproteinases

ZBP1 - Zipcode-Binding Protein 1 


\section{Sumário}

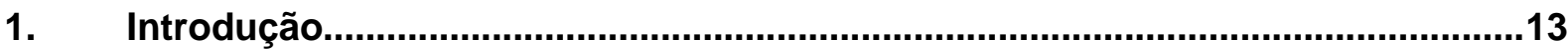

1.1. Doenças Neurodegenerativas.............................................................13

1.2. Doença de Parkinson...............................................................................13

1.3. A relação entre a Doença de Parkinson e o ciclo sono-vigília .................15

1.4. O papel do microambiente na homeostase do cérebro adulto.................18

1.5. A matriz extracelular cerebral...................................................................19

1.6. Metaloproteinases de Matriz e seus inibidores..........................................19

1.7. Mudanças no microambiente e a consolidação da memória.....................21

1.8. MMPs na Doença de Parkinson...............................................................24

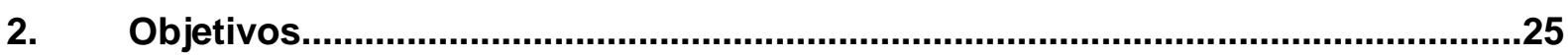

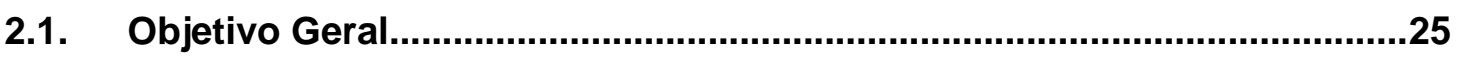

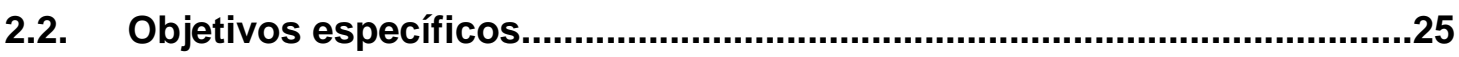

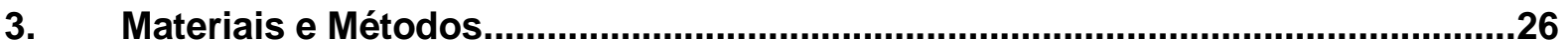

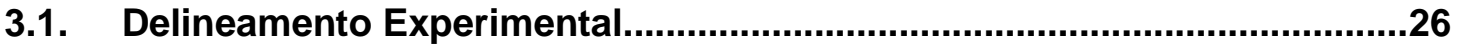

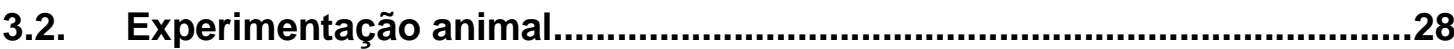

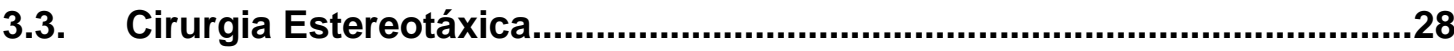

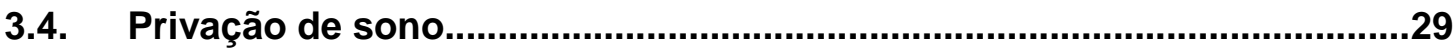

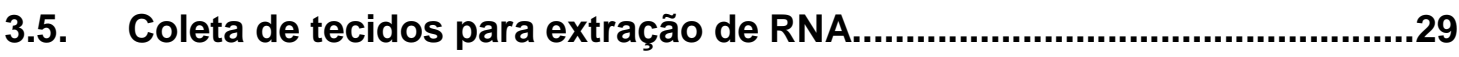

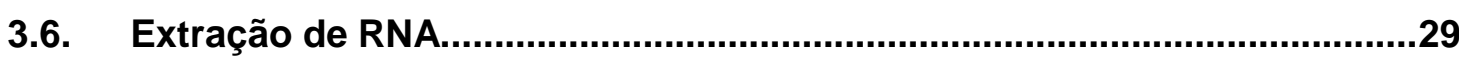

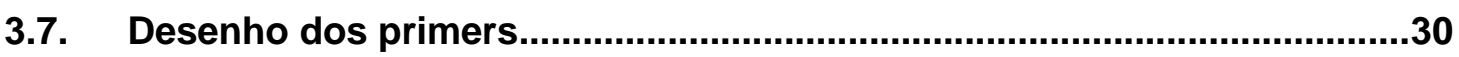

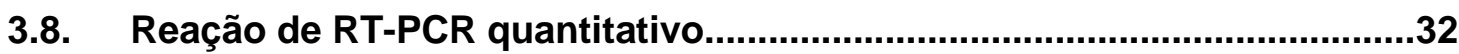

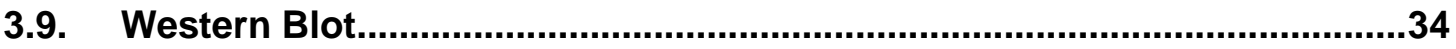

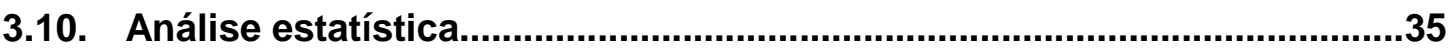

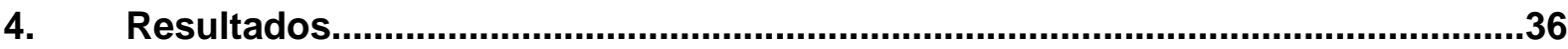

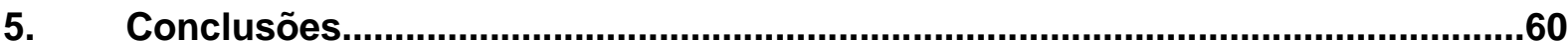

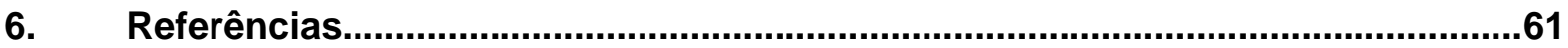




\section{Resumo}

Spindola A. Análise do perfil de expressão de metaloproteinases (MMPs) e seus inibidores, Timp e Reck, em modelo animal de Doença de Parkinson. [tese]. São Paulo: "Instituto de Ciências Biomédicas, Universidade de São Paulo"; 2019.

A Doença de Parkinson (DP) é a a segunda doença neurodegenerativa mais comum no mundo. Dentro dos sintomas não-motores, desordens do sono são extremamente comuns e tem sido relacionado com perturbações cognitivas e da memória. O microambiente celular, em particular a Matriz Extracelular (MEC), está profundamente envolvida no processo de consolidação da memória assim como em processos neuropatológicos, como neuroinflamação, danos na barreira hematoencefálica e morte celular. Para melhor entendimento das dinâmicas da MEC nos distúrbios de memória que ocorrem na DP, o presente estudo investiga as expressões orquestradas das Mmps (Mmp-3, Mmp-7 e Mmp-9), e seus moduladores (Reck e Timp-3) em modelo animal de DP induzido por rotenona, onde foi adicionada uma intervenção no processo de memória por introdução da privação do sono REM (PSREM). Adicionalmente, foi determinada a correlação da expressão de Mmp-7 e Mmp-9 com fatore neurotroficos, Gdnf e Ngf, e os receptores de dopamina Drd1 e Drd2. A PSREM reverteu as deficiências cognitivas induzidas pela rotenona. Associado a este fenótipo, observamos um aumento significativo na razão da expressão de mRNA de Mmp7/Reck e Mmp-9/Reck na substancia nigra e a razão Mmp-9/Reck no hipotálamo. Além disso, a correlação positiva das razões de expressão de Mmp/Reck entre a substância nigra e o estriado observada na infusão de rotenona é revertida pela PSREM. Em conjunto, nossos resultados sugerem uma potencial associação orquestrada entre um aumento nas relações de expressão Mmp-7 e -9/Reck na substantia nigra e um efeito positivo no desempenho cognitivo em indivíduos afetados pela PD.

Palavras-Chave: Doença de Parkinson, Privação de sono, Reck, Mmp-9, Mmp-7, dinâmica da matriz extracelular 


\begin{abstract}
Parkinson's disease (PD) is the second most common neurodegenerative disorder worldwide. Among its non-motor symptoms, sleep disorders are extremely common and have been linked to cognitive and memory disruption. The microenvironment, in particular the extracellular matrix (ECM), is deeply involved in memory consolidation as well as in neuropathological processes such as inflammation, damage to the bloodbrain barrier, and neuronal death. To better understand ECM dynamics in PD memory disturbances, the present study investigates the orchestrated expression of Mmps (Mmp-3, 7 and 9) and their modulators (Reck and Timp-3) in a rotenone-induced PD model in which an additional intervention in the memory process was introduced through rapid eye movement sleep deprivation (REMSD). Additionally, the correlation of Mmp-7 and -9 expression to the neurotrophic factors $\mathrm{Ngf}$, Gdnf, and the dopamine receptors $D 1$ and $D 2$ was determined. REMSD reversed the rotenone induced cognitive impairments. Associated to this phenotype, we observed a significant increase in Mmp-7/Reck and Mmp-9/Reck mRNA expression ratio in the substantia nigra, and $M m p-9 / R e c k$ ratio in the hypothalamus. Moreover, the positive correlation of $M m p / R e c k$ expression ratios between the substantia nigra and the striatum observed upon rotenone infusion is reversed by REMSD. Taken together, our results suggest a potential orchestrated association between an increase in Mmp-7 and 9/Reck expression ratios in the substantia nigra and a positive effect on cognitive performance in subjects affected by PD.
\end{abstract}

Keywords: Parkinson's Disease, Sleep deprivation, Reck, Mmp-9, Mmp-7, Extracellular matrix dynamics. 


\section{INTRODUÇÃO}

\subsection{Doenças Neurodegenerativas}

Doenças neurodegenerativas são incuráveis, resultando na degeneração e/ou na morte das células nervosas. Estas patologias incluem: Doença de Alzheimer, Doença de Parkinson, Doença de Huntington, Doença do Neurônio Motor, Doença de Creutzfeldt-Jakob e Esclerose Múltipla. Estas condições estão fortemente relacionadas com o envelhecimento, sendo estimado que, apenas os casos de Demência, custem cerca de 17 bilhões de libras por ano à população Europeia (Medical Research Council, 2015).

\subsection{Doença de Parkinson}

A doença de Parkinson é uma condição neurodegenerativa na qual ocorre a morte de neurônios dopaminérgicos da Substancia Nigra, levando a sintomas motores como: tremores, bradicinesia e rigidez, além de sintomas não-motores como: perda do sentido de olfato, transtornos de humor, depressão e ansiedade (1).

A cascata de oxidação dopaminérgica é uma via complexa, na qual ocorre a formação de três produtos: dopamina orto-quinona, aminocromo e 5,6indolequinona (2). Esta via tem participação importante em processos neurodegenerativos que ocorrem na Doença de Parkinson, já que o acúmulo de aminocromo induz disfunção mitocondrial, formação de fibrilas de alfa-sinucleína e estresse oxidativo, o que desencadeia uma resposta neurotóxica $(3,4)$. A redução do aminocromo é catalisada pela enzima DT-diaforase (NQO1), que apresenta um papel neuroprotetor em neurônios dopaminérgicos (5). $\mathrm{Na}$ presença da NQO1, ocorre a redução do aminocromo por dois elétrons, formando o leuco-aminocromo, que não é citotóxico. Porém, na ausência dessa enzima, ocorre a redução parcial do aminocromo por apenas um elétron, levando à formação de leuco aminocromo o-semi-quinona, que é uma potente toxina para neurônios dopaminérgicos $(2,3,6)$.

Também importante para a patologia da PD é o Fator de Indução de Apoptose (AIF), proteína que, em células saudáveis, está localizada na membrana mitocondrial. Porém, quando a célula sofre algum tipo de injúria, AIF 
é translocada para o núcleo, induzindo condensação da cromatina e desfragmentação do DNA (7).

\subsubsection{Modelos animais utilizados no estudo de Doença de Parkinson}

O uso de animais para estudar os diferentes aspectos do fenótipo da Doença de Parkinson tem permitido o estudo tanto da progressão da doença quanto de possíveis tratamentos. Os compostos utilizados nestes modelos resultam na aparição de marcadores neuropatológicos da Doença de Parkinson, como a morte de neurônios dopaminérgicos da Substancia Nigra pars compacta, formação dos corpúsculos de Lewy, defeitos na função mitocondrial, disfunção do sistema Ubiquitina-proteossoma, e alterações na formação de radicais livres (8)

\subsubsection{6-OHDA}

A 6-hidroxidopamina foi o primeiro composto a ser descrito por causar lesão nos neurônios dopaminérgicos do sistema nigrostriatal em ratos (9), sendo uma molécula análoga à Dopamina, com alta afinidade pelos receptores dopaminérgicos, que vão transportar a droga para o interior do neurônio (10). Quando injetada, a 6-OHDA causa progressiva degeneração dos neurônios dopaminérgicos $(11,12)$, porém não é possível observar a formação dos corpúsculos de Lewy (13).

\subsubsection{MTTP}

1-methyl-4-phenyl-1,2,3,6-tetrahydropyridine (MPTP) é uma neurotoxina que causa dano na via dopaminérgica do sistema nigrostriatal, através da significativa morte dos neurônios dopaminérgicos da Substancia Nigra e do Estriato (14). Uma vez internalizada pelos neurônios dopaminérgicos, a droga é acumulada nas mitocôndrias, bloqueando a cadeia transportadora de elétrons e inibindo o complexo 1 da mitocôndria (15). 


\subsubsection{PARAQUAT}

$N, N^{\prime}$-dimethyl-4,4' -bipyridinium dichloride (Paraquat) causa estresse oxidativo nas células do sistema nervoso através da geração de espécies reativas de oxigênio, o que causa a morte dos neurônios dopaminérgicos da substancia nigra e induz a formação de corpúsculos de Lewy $(16,17)$. Porém, há contradições quanto ao uso de Paraquat: alguns estudos não encontraram relação entre o Paraquat e alterações no sistema dopaminérgico nigrostriatal (16-18).

\subsubsection{ROTENONA}

O modelo selecionado para este estudo, a Rotenona, bloqueia a cadeia transportadora de elétrons da mitocôndria através da inibição do complexo 1, como visto na MPTP, bloqueia também a mitose e inibe a proliferação celular (19). Este sistema reproduz os principais sintomas da Doença de Parkinson, incluindo a formação dos corpúsculos de Lewy, degeneração dos neurônios dopaminérgicos do sistema nigrostriatal (20), e, por ser altamente lipofílico, atravessa facilmente a barreira-hematoencefálica (21).

\subsection{A relação entre a Doença de Parkinson e o ciclo sono-vigília}

\subsubsection{A importância do sono}

O sono é definido como um estado natural e reversível de redução de respostas a estímulos externos, acompanhado pela perda de consciência e relativa inatividade (22). O sono ocorre de maneira intervalada, sendo regulado homeostaticamente (23). O sono em roedores é dividido em sono não-REM (fase I e fase II, sendo ambas chamadas de sono de ondas lentas, ou Slow-Wave Sleep - SWS) e sono REM.

O período de sono tem se mostrado responsável por melhorar a consolidação da memória. Além de regular o metabolismo do tecido cerebral e reduzir a fadiga mental, durante o sono, o cérebro remove toxinas que foram se acumulando ao longo do dia, decorrentes do metabolismo cerebral $(24,25)$. 
A hipótese de que o sono contribui para a consolidação da memória tem sido reforçada devido a algumas evidências, como, por exemplo, a observação de que a expressão de algumas proteínas que são necessárias para a plasticidade sináptica, como ARC (Activity-Regulated Cytoskeleton-associated protein), BDNF (Brain-Derived Neurotrophic Factor) e PSD-95 (PostSynaptic Density protein 95), aumentam durante as horas mais iniciais do sono $(26,27)$. Além disso, durante o desenvolvimento inicial, que compreende o período entre o final da fase fetal e o início da fase neonatal, de animais que não apresentam qualquer distúrbio de sono, ocorre o aumento do número de sinapses (28). A formação de novas espinhas dendríticas, que são pequenas extensões que ocorrem nos dendritos, e de novas sinapses durante o sono, sugere que a consolidação da memória ocorra durante este período $(29,30)$.

\subsubsection{As consequências da privação de sono}

A repetida perda de sono tem consequências severas para a função, desempenho e bem-estar geral do cerebro (31-33). No entando, a perda crônica de sono tem sido relacionada como um fator de risco para várias desordens com consequências fatais à médio e longo prazo (34)

Evidências derivadas de pesquisas tanto com humanos quanto com animais indicam que até mesmo um curto período de privação de sono pode afetar negativamente a função cerebral, como: atenção, tomada de decisão e diversas formas de memória (35-37).

Interessantemente, estudos recentes investigaram tipos específicos de memória e revelaram que o hipocampo é especialmente vulnerável às consequências negativas da privação de sono (35,38-40). Por exemplo, até mesmo uma única noite de privação de sono pode prejudicar a consolidação de memória dependente do hipocampo (35,38-40).

A privação de sono e as perturbações do sono podem causar graves problemas cognitivos e emocionais (41). Além disso, podem prejudicar a formação de memória em tarefas complexas, como tarefas de aprendizado em labirintos (42). 
O uso da privação de sono em animais tem se mostrado consistente para evidenciar o papel do sono no processo de consolidação da memória após tarefas de aprendizados. Existe um grande número de trabalhos que abordam a relação entre sono e memória. De modo geral, há duas abordagens básicas para o estudo desta relação. Uma estratégia é registrar as mudanças nos estados de sono após a aquisição de tarefa (43-45), a segunda é realizar a privação de sono após a aprendizagem e, em seguida, avaliar os efeitos desta privação na memória destes animais (46-48)

Além disto, ratos vivendo em um ambiente enriquecido, apresentaram um aumento no sono REM quando comparados ao grupo controle (49), e roedores que sofreram privação de sono antes do treinamento mostraram uma perda da memória espacial em testes de labirinto radial e labirinto aquático de Morris $(50,51)$. Há evidencias de que o sono é importante para o aprendizado e a memória, sendo o déficit de sono prejudicial à performance em testes de memória tanto em roedores quanto em humanos (52). No entanto, o papel do sono na formação da memória é complexo e aparenta depender da natureza da tarefa que é apresentada (53).

\subsubsection{Alterações no ciclo vigília-sono observados na Doença de Parkinson}

Além da sintomatologia mencionada anteriormente, a doença de Parkinson apresenta sintomas relacionados à desregulação do sono, como: o distúrbio comportamental do sono REM, a síndrome das pernas inquietas, além de fragmentação do sono e sonolência (54). No Distúrbio Comportamental do Sono REM a atonia muscular que ocorre durante o sono REM é enfraquecida e, como consequência, ocorrem movimentos involuntários durante o sono, como chutes e contrações musculares (55). Distúrbios do sono afetam drasticamente a qualidade de vida dos pacientes com Parkinson, e, geralmente, precedem as complicações motoras (56).

A neuropatologia do Parkinson afeta anatomicamente estruturas que estão envolvidas na modulação da fisiologia do ciclo de sono (57). O balanço do 
neurotransmissor dopamina sugere um envolvimento dopaminérgico na regulação do sono, já que distúrbios de sono acontecem tanto na falta de dopamina, como aqueles que ocorrem na Doença de Parkinson (58), onde os pacientes apresentam sonolência, diurna e noturna e aumento na duração do sono REM (59), quanto no excesso de dopamina, como o que ocorre na esquizofrenia, levando os pacientes a sofrerem de uma expressiva insônia durante a noite $(60,61)$.

Foi descrito que animais submetidos tanto à privação de sono, quanto à lesão da Substancia Nigra provocada por Rotenona, isoladamente, apresentam um déficit em tarefas de reconhecimento de objetos (62). Neste teste, em um primeiro momento, cada animal foi colocado em um ambiente restrito para explorar dois objetos idênticos. Após a fase de exploração, um dos objetos foi trocado por um novo e o animal foi recolocado no ambiente de modo a explorar estes objetos. O tempo durante o qual o animal passou investigando cada um dos objetos foi registrado. Ambos os grupos de animais (submetido à privação de sono REM e ao tratamento com rotenona, para simulação da Doença de Parkinson) apresentaram um fenótipo semelhante, não distinguindo entre 0 objeto previamente conhecido e o objeto novo, passando o mesmo tempo investigando tanto o objeto novo quanto o objeto que já lhe era familiar. 0 resultado de Dos Santos e colaboradores pode sugerir que a consolidação ou retenção dos processos que atuam na memória de reconhecimento foram prejudicadas. Porém, curiosamente, quando os animais foram submetidos aos dois procedimentos combinados, não foi observado o comprometimento da memória e os animais passaram mais tempo investigando o objeto novo, mostrando que quando combinados, estes modelos não necessariamente causam uma redução na cognição (62).

\subsection{O papel do microambiente na homeostase do cérebro adulto}

A dinâmica do microambiente que circunda as células, composta pela Matriz Extracelular (ECM), células estromais e células inflamatórias infiltradas, tem um papel fundamental tanto para homeostase dos tecidos quanto para 0 desenvolvimento $(63,64)$. 
A ECM é composta por uma grande variedade de macromoléculas de diferentes naturezas, incluindo glicosaminoglicanos, proteoglicanos e glicoproteínas. A interação entre a ECM e as células residentes no tecido ocorre diretamente através de receptores de superfície para elementos da ECM, como as integrinas e os sindecanos. Devido à sua complexidade, a ECM não só atua como um suporte físico para as células que compõem um determinado tecido, mas, também, é um reservatório de fatores de crescimento, citocinas, diferentes inibidores, hormônios, entre outras moléculas importantes na homeostase tecidual. Desta forma, a ECM propicia a interação entre diferentes tipos celulares no âmbito célula-célula, promovendo uma interação, em escala sistêmica, através da difusão de moléculas sinalizadoras $(63,64)$.

\subsection{A matriz extracelular cerebral}

O tecido cerebral é composto de uma matriz extracelular específica e dois tipos principais de células: os neurônios e as células da glia, as quais são

subdivididas em astrócitos, oligodendrócitos, 19atalisada e células ependimárias. A matriz extracelular representa uma rede molecular que circunda as células do cérebro, podendo ocupar cerca de $20 \%$ de todo volume cerebral (65). As moléculas da MEC são produzidas pelo Aparato de Golgi dos neurônios e das células da glia (66-68). As moléculas da MEC são importantes para o desenvolvimento do cérebro adulto $(69,70)$. As interações entre as moléculas da MEC e os diversos receptores de superfície celular são essenciais para diversas funções da MEC, como migração, proliferação, diferenciação, sinaptogenesis e atividade sináptica $(69,71)$.

A ECM presente no tecido cerebral adulto normal é escassa em componentes fibrilares como: colágeno, fibronectina e vitronectina e em proteínas da membrana basal, como a laminina, apesar destes componentes serem abundantes no cérebro embrionário. Por outro lado, é enriquecida em ácido hialurônico, glicoproteínas da família das lectinas (como versican e neurocan), trombospondina, tenascina $\mathrm{C}$ e $\mathrm{R}$, entre outros, sendo uma matriz altamente hidratada (72-74).

\subsection{Metaloproteinases de Matriz e seus inibidores}

A degradação da ECM é mediada por algumas famílias de proteinases 
extracelulares que incluem as serino-proteases, cisteíno-proteases, Adams ( $A$ Disintegrin and Metalloprotease) e Metaloproteinases de Matriz dependentes de zinco (Mmps) (75). As Mmps são enzimas zinco-dependentes que, juntamente com seus inibidores, Timps (Tissue Inhibitors of Metalloproteinases) e Reck (Reversion-inducing-Cysteine-rich protein with Kazal motifs), são cruciais para o remodelamento da ECM. Esse remodelamento é essencial para vários processos durante o desenvolvimento do Sistema Nervoso Central, incluindo proliferação, diferenciação e migração celular, crescimento axonal, mielinogenesis, angiogenesis e remodelamento sináptico (76,77). Assim, o envolvimento de Mmps e seus reguladores não é limitado a injurias, constituindo, também, componentes da fisiologia normal do cérebro, incluindo a formação de novas redes neurais envolvendo aprendizado e memória $(78,79)$.

As MMPs são secretadas na forma de uma proteína inativa, que é ativada por clivagens 20atalisadas por proteases extracelulares, sendo classificadas de acordo com o substrato que degradam (80). A MMP-3 pertence à família das estromelisinas, e a MMP-7 à família da matrilisinas, e ambas atuam na degradação de fibronectina, laminina, elastina e colágeno IV (81-84). A MMP-9 pertence à família das gelatinases e degrada elastina, fibrilina, gelatina e colágeno (IV, V, VII, X e XIV) (84).

Foi demonstrado que o gene RECK (Reversion-inducing Cysteine-rich protein with Kazal motifs) regula negativamente a atividade de, pelo menos, quatro membros da família de Metaloproteinases de Matriz, a saber: MMP-2, MMP-7, MMP-9 e MMP-14 (MT1-MMP) (Figura 1) (85-87). Outros alvos de RECK foram identificados, como a metaloproteinase $A D A M 10$, e a ectopeptidase de membrana CD13/ Aminopeptidase N (88,89). Além disto, foi descrito o envolvimento de RECK na estabilização de adesões focais e da polaridade celular anterior-posterior (90). Camundongos nocauteados, com falta de Reck funcional, morrem em torno do décimo dia embrionário, mostrando uma organogênese anormal, alterações na membrana basal com privação de colágeno fibrilar e elevado nível da atividade de Mmps (85). Durante o desenvolvimento do córtex de embriões de rato, Reck estimula a via de sinalização de Notch, sendo especificamente expresso em células precursoras neurais (NPCs) Nestina-positivas. NPCs deficientes em Reck sofrem 
diferenciação precoce devido a um enfraquecimento da sinalização de Notch e, consequentemente, da sua capacidade de auto-renovação (91).

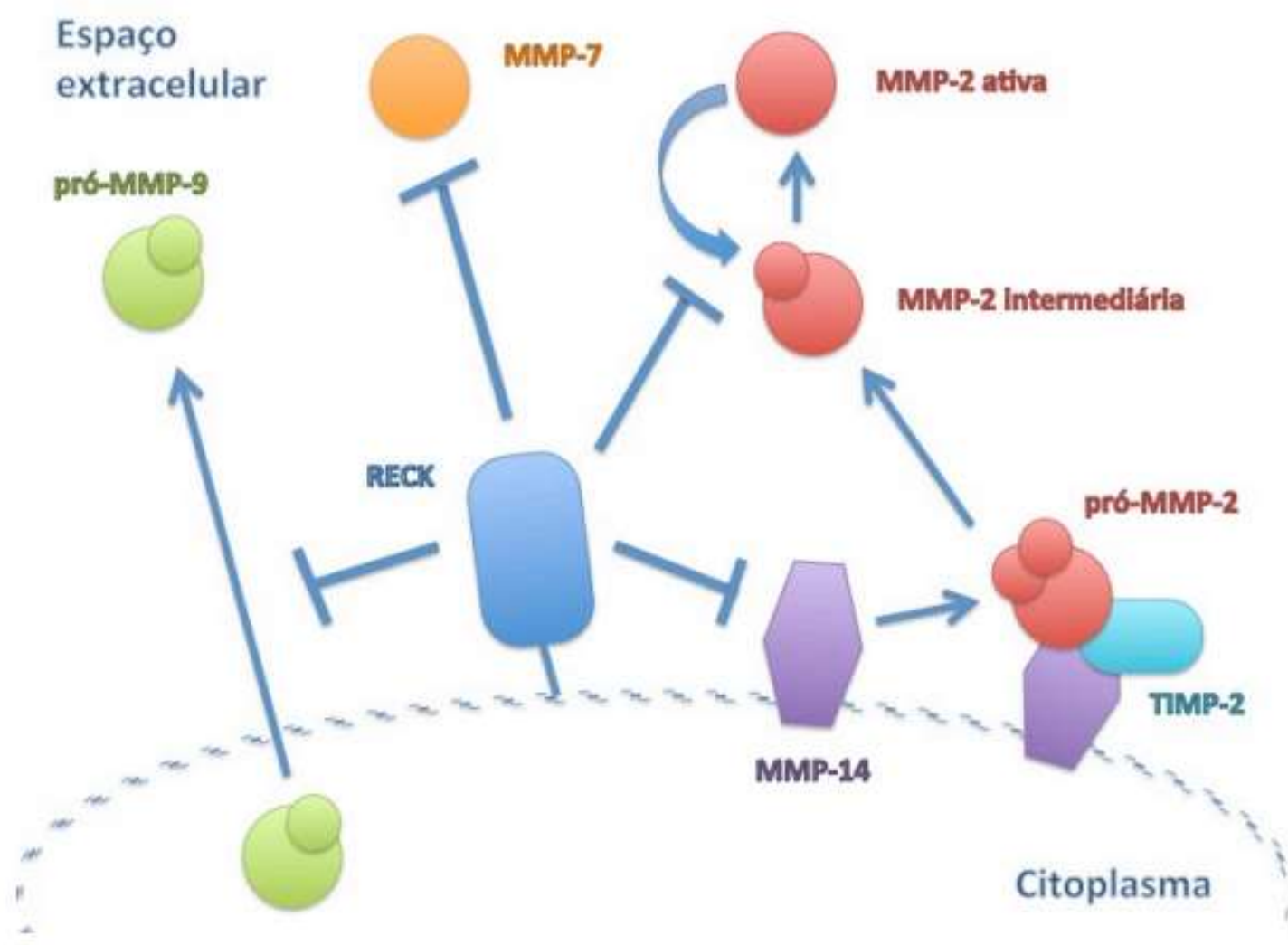

Figura 1: Regulação da atividade das MMPs por RECK. RECK inibe a atividade de $M M P-7$ e $M M P-14$, a ativação da pró-MMP-2 e a secreção da $M M P$ 9. RECK regula a atividade e secreção da $M M P-9$, sendo a única $M M P$ descrita também como sendo regulada transcricionalmente por $R E C K$. Por inibir a atividade da MMP-14, RECK inibe a formação do complexo ternário TIMP-2, pró$M M P-2$ e $M M P-14$, inibindo a cascata de ativação da MMP-2. Além disto, também inibe a etapa auto-proteolítica final necessária para a ativação de MMP2 (Adaptado de Trombetta-Lima et al, 2015).

\subsection{Mudanças no microambiente e a consolidação da memória}

Formar e recuperar memórias é uma capacidade fundamental para a sobrevivência de qualquer organismo vivo, permitindo-lhe adaptar seu comportamento de acordo com as exigências de um ambiente em constante 
mudança, selecionando e melhorando adequadamente seu comportamento em relação a determinadas situações, como por exemplo, locais de forrageamento e a situações que causariam algum tipo de perigo à vida do organismo (92).

Ao nível neuronal, a formação de memória se baseia em mudanças na força e estrutura das conexões sinápticas, assim como na reestruturação da matriz extracelular circundante, sendo as Mmps enzimas cruciais neste processo (93). Estudos em ratos mostraram que ocorre um aumento na atividade de Mmp9 no hipocampo após uma tarefa de aprendizado, como o labirinto aquático de Morris, atingindo seu pico no quinto dia após o treinamento (94). Foi observado, também, que o bloqueio da atividade de Mmps utilizando-se um inibidor para Mmp-2/-9 de amplo espectro, resultava na diminuição do aprendizado por medo nestes animais. No ensaio em questão, os animais foram colocados em uma caixa contendo um lado claro e um lado escuro, os quais estavam isolados um do outro, sendo que, neste último, havia uma grade eletrificada no chão. Em um primeiro momento, os animais eram colocados na parte clara da caixa, e quando estes se moviam para a parte escura, recebiam um choque (1,6mA, por 2seg). Ao longo do treinamento, animais selvagens para Mmp-2/9 tendiam a passar mais tempo na parte clara da caixa, evitando entrar na região escura (93). Em contrapartida, camundongos deficientes em Mmp-9 não apresentaram este padrão de comportamento, no qual haveria um aumento no tempo em que passavam na região clara da caixa conforme o avanço do treinamento; ao invés disso, apresentavam o mesmo comportamento dos animais que não foram treinados (95).

Existem algumas evidências que sugerem que o sono atua na etapa de consolidação da memória, no entanto, o papel preciso do sono em cada uma das etapas ainda não está totalmente esclarecido (96). Assim, por exemplo, em alguns estudos, o sono de ondas curtas (Slow Wave Sleep - SWS) tem sido associado a memórias declarativa e espaciais $(97,98)$. Outros estudos sugerem que o sono REM está associado ao processo de aprendizagem do período de vigília.(Cicogna, Cavallero, \& Bosinelli, 1986; Cavallero, 1993; Nielsen, 2000)

Estudos recentes mostraram que os componentes da MEC estão envolvidos na regulação da plasticidade sináptica (102). A produção da MEC 
pelo cérebro maduro depende da atividade neuronal. Mudanças na MEC levam a alterações no número de sinapses e alterações no número e na densidade dos receptores na superfície dos neurônios (68). Uma vez que a MEC é um sistema multicomponente, diferentes elementos podem impactar, de formas diferentes, a transmissão sináptica. Mudanças nas moléculas da MEC podem causar alterações na transmissão sináptica, além de levar a alterações nos processos de aprendizagem e memória (103).

Animais submetidos a testes comportamentais apresentaram a ativação tanto de MMP-9 quanto de MMP-3, enquanto que a inibição destas enzimas causa uma redução na aprendizagem e habituação às novas condições (104). Em condições normais, a ativação da MMP-9 contribui para o remodelamento da MEC local $(79,105)$

A memória pode ser dividida em três sub-processos, a saber: codificação, consolidação e recuperação. Durante a codificação, a percepção de novos estímulos resulta na formação de um novo traço de memória, que é frágil e altamente susceptível a distúrbios de esquecimento. Durante a consolidação, o traço de memória que era, até então, frágil, vai gradativamente se estabilizando, possivelmente envolvendo múltiplas ondas de potencias de ação curtos e longos, os quais servem para fortificar e integrar esses novos traços de memórias à rede de conhecimento já existente. Durante a recuperação, a memória já armazenada é acessada (92).

Existem dois tipos principais de memória: de curta duração, a qual dura apenas por algumas horas; e a memória de longa duração, a qual dura por anos, requerendo inúmeros processos, produção de novos RNAs mensageiros e proteínas relacionadas com a plasticidade sináptica (106). Alguns dos genes expressos estão relacionados com a reorganização do citoesqueleto dos neurônios pré- e pós-sinápticos, como a ZBP1 (Zipcode-Binding Protein 1), que regula a atividade da beta-actina nos dendritos dos neurônios (107), a Sam68 (Src-Associated in Mitosis $68 \mathrm{KDa}$ ), que é crucial para o transporte do mRNA de beta-actina, regulando os níveis de mRNA e proteína da beta-actina nos compartimentos dos dendritos sinápticos (108). 


\subsection{MMPs na Doença de Parkinson}

As Mmps já foram implicadas em processos neuropatológicos que ocorrem na Doença de Parkinson, como: inflamação, dano na barreira hemato-encefálica e morte neuronal (109). A MMP-3 é amplamente distribuída pelo cérebro, sendo envolvida em processos como: crescimento axonal, migração neuronal e sinaptogenesis $(110,111)$, e, também, na plasticidade sináptica que ocorre nos processos de aprendizagem e memória (112). Em contraste com estas funções, estudos in vitro demonstraram que a MMP-3 é liberada por neurônios apoptóticos, causando ativação da micróglia e aumento dos processos inflamatórios (113), aumentando as evidências de que a MMP-3 tem um papel importante em patologias neuro-degenerativas como: Doença de Alzheimer, demência vascular, isquemia e Doença de Parkinson (114). Além disso, a MMP3 apresenta uma imuno-reatividade mais elevada na Substancia Nigra de ratos submetidos à 6-hidroxidopamina (6-OHDA) (115). Em cérebros de pacientes, durante a análise post-mortem, foi observadoque a-sinucleína e Mmp-3 estão co-localizadas com os corpúsculos de Lewy, agregados fibrilares da proteína alfa-sinucleína (116)(117). Além disto, MMP-3 participa da morte dos neurônios dopaminérgicos através da clivagem da $\alpha$-sinucleína, tanto in-vivo, quanto invitro (117).

Estudos recentes demonstraram que a expressão de Mmp-9 tem papel importante nos processos de neuro-inflamação e ativação da micróglia, envolvidos com a morte dos neurônios dopaminérgicos (118,119). Produzida também por neurônios e micróglia, a $M m p-9$ é mais expressa no Estriado e na Substancia Nigra em pacientes com Doença de Parkinson (120). A expressão de Mmp-9 está associada à morte dos neurônios dopaminérgicos, sendo elevada em modelos animais de Doença de Parkinson, e quando um inibidor de MMP é utilizado, ocorre a supressão da morte dos neurônios dopaminérgicos (121). Aparentemente, a MMP-9 participa dos estágios mais iniciais da Doença de Parkinson, já que não ocorre aumento significativo em sua expressão em cérebros de pacientes portadores desta doença (122).

Neste contexto, o presente trabalho tem como Objetivo a análise da expressão orquestrada dessas enzimas e seus moduladores em modelo de 
Doença de Parkinson, com alteração no processo de consolidação da memória, visando contribuir para o esclarecimento do papel destas enzimas na referida patologia. Com este fim, ratos Wistar adultos foram submetidos à injeção estereotáxica de rotenona, como modelo de Doença de Parkinson, e à privação de sono REM, de modo a induzir uma alteração no processo de consolidação de memória, isoladamente ou em combinação. Os animais submetidos à injeção de rotenona ou à privação de sono de forma isolada apresentaram um déficit em seus desempenhos cognitivos. Curiosamente, os animais submetidos a ambos os procedimentos apresentaram desempenho cognitivo comparado ao grupo controle. Este melhor desempenho cognitivo foi acompanhado por uma maior razão da expressão de Mmp-9 e Mmp-7 em relação à expresão de Reck na substancia nigra. Um perfil similar foi observado para a razão de expressão de Mmp-9 em relação à expressão de Reck no hipotálamo. Nossos resultados sugerem que um maior remodelamento da MEC no hipotálamo e na substancia nigra, tem um potencial efeito benéfico no desempenho cognitivo em indivíduos com Doença de Parkinson. Os resultados dessa dissertação estão sendo apresentados no formato de artigo original de pesquisa, o qual foi elaborado e submetido à publicação.

\section{Objetivos}

\subsection{Objetivo Geral}

Analise do perfil de expressão de Mmps e de seus inibidores Timpse Reck em cérebros de ratos adultos submetidos a modelos de privação de sono REM e/ou Doença de Parkinson, isoladamente ou em combinação.

\subsection{Objetivos específicos}

2.2.1. Análise do perfil de expressão de Mmps, Timps e Reck em cérebros de ratos adultos submetidos, de forma isolada ou em combinação, a modelos de privação de sono REM e de Doença de Parkinson, através de qRT-PCR e Western Blot. Foram analisadas as seguintes estruturas: Hipocampo, Hipotálamo, Estriado e Substancia Nigra. 
2.2.2. Análise comportamental para avaliação de memória em ratos adultos submetidos, de forma isolada ou em combinação, a modelos de privação de sono REM e de Doença de Parkinson.

\section{Materiais e Métodos}

\subsection{Delineamento Experimental}

Para perseguir os objetivos propostos por este projeto, ratos Wistar foram adotados como modelo experimental e submetidos à: (i) injeção de rotenoma, como modelo para Doença de Parkinson; (ii) privação de sono REM (PSREM), de forma isolada ou em combinação. Assim, os animais utilizados para este estudo foram divididos em quatro grupos: (i) Sham controle, no qual os animais foram submetidos à cirurgia estereotáxica para injeção de DMSO, porém não foram submetidos à privação de sono REM; (ii) rotenona controle, no qual foram submetidos à cirurgia esterotáxica para aplicação de rotenona mas não foram submetidos à privação de sono REM ; (iii) Sham PSREM, no qual foram submetidos à cirurgia estereotáxica para aplicação de DMSO e à privação de sono REM; (iv) rotenona PSREM, no qual foram submetidos tanto à cirurgia esterotáxica para administração de rotenona quanto à privação de sono REM (Figura 2A). A estratégia experimental empregada consistia na realização da cirurgia estereotáxica para aplicação de rotenona ou DMSO na Substância Nigra, utilizando-se as coordenadas (tendo o bregma como referência): $(A P)=$ $-5,0 \mathrm{~mm},(\mathrm{ML})= \pm 2,1 \mathrm{~mm}$ e $(\mathrm{DV})=-8,0 \mathrm{~mm}$, dos animais no dia 0. Após 7 dias, os animais foram submetidos (ou não) à privação de sono REM por $24 \mathrm{~h}$, sendo eutanasiados ao final desse período (Figura 2B). O tecido cerebral dos animais foi então coletado para a análise de expressão gênica por qRT-PCR e Western Blot (Figura 2C). 


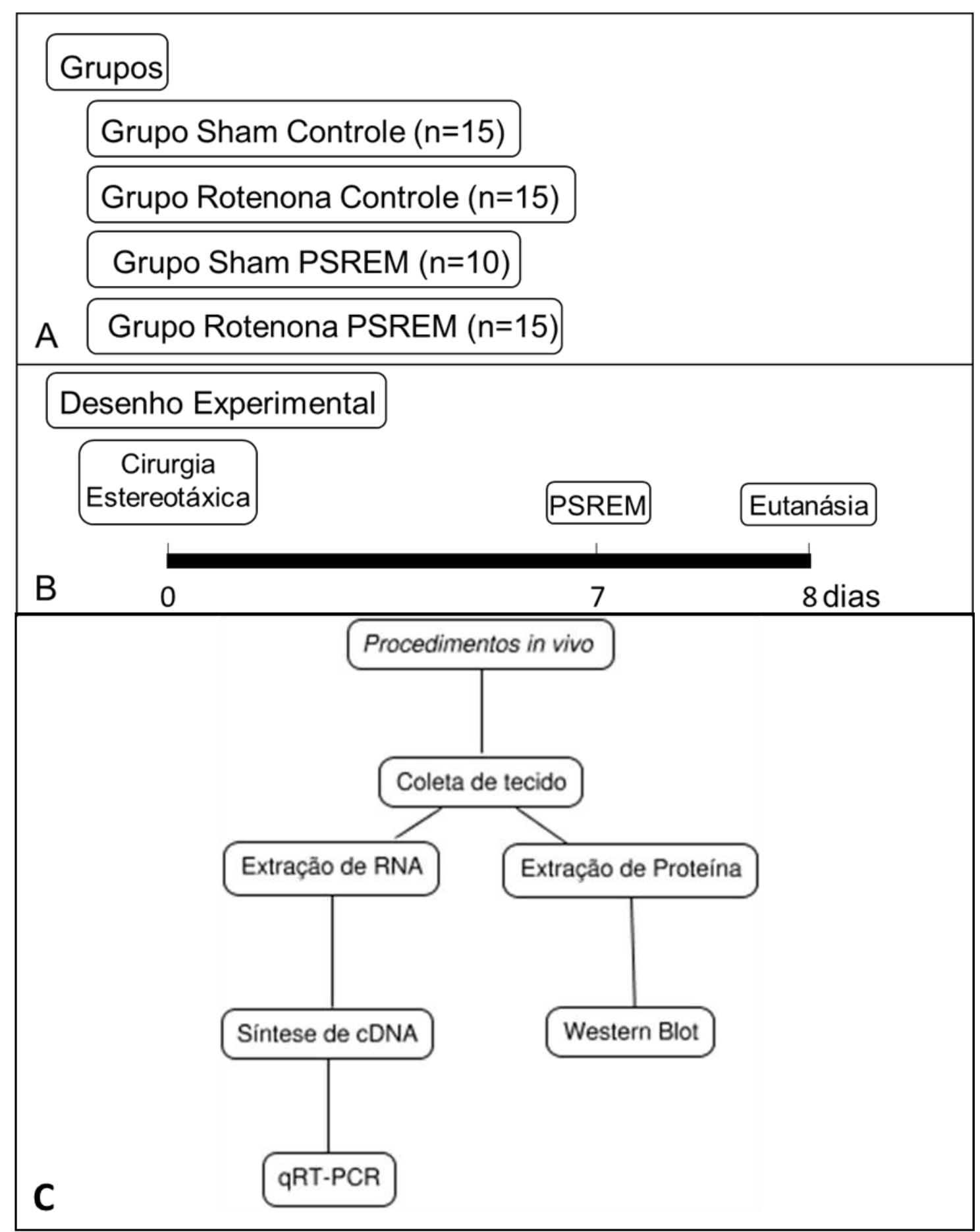

Figura 2: Fluxograma da estratégia experimental utilizada no presente trabalho. (A) Grupos experimentais; (B) desenho experimental; (C) processamento das amostras. 


\subsection{Experimentação animal}

Toda a experimentação animal foi realizada em colaboração com o grupo do Professor Dr. Marcelo de Meira Santos Lima, e nas dependências de seu laboratório na Universidade Federal do Paraná. Os experimentos foram realizados em conformidade com as diretrizes preconizadas pelo CEUA/BIO da Universidade Federal do Paraná (Protocolo aprovado n. 857, ANEXO I).

Foram utilizados ratos Wistar machos, com 90 dias, pesando entre 280320 gramas no início do experimento. Os animais foram mantidos em grupos de cinco em caixas apropriadas, sob condições controladas de temperatura (22 $+2^{\circ} \mathrm{C}$ ) e ciclo claro-escuro de 12 horas (7:00-19:00). Os animais foram mantidos com livre acesso à comida e água.

\subsection{Cirurgia Estereotáxica}

Os animais receberam xilazina intraperitonealmente $(10 \mathrm{mg} / \mathrm{kg})$ e, após a sedação inicial, foram então anestesiados com quetamina (90 mg/kg). Para a infusão de rotenona na Substancia Nigra (SN), as coordenadas, (tendo o bregma como referência) foram: $(A P)=-5,0 \mathrm{~mm},(M L)= \pm 2,1 \mathrm{~mm}$ e $(D V)=-8,0$ $\mathrm{mm}$ (123). As agulhas foram posicionadas nas regiões de interesse para a infusão bilateral de $1 \mathrm{~mL}$ da neurotoxina rotenona (12 mg/mL), com auxílio de uma bomba eletrônica (Insight Instruments, Ribeirão Preto, Brasil) e microseringa de $10 \mathrm{~mL}$ (Hamilton Apparatus) a uma taxa de infusão de $0,33 \mathrm{~mL} / \mathrm{min}$, durante 3min. Animais do grupo Sham receberam apenas o veículo dimetilsulfóxido (DMSO), em iguais condições. A Rotenona é um herbicida e inseticida, com meia vida variando de 3 a 5 dias. É um composto altamente lipofílico, o que the confere a característica de atravessar facilmente barreiras biológicas, como a membrana celular mitocondrial e a barreira hematoencefálica (124), podendo ser administrada sistemicamente através de várias rotas, como: subcutânea, intravenosa, intraperitoneal e através de cirurgia estereotáxica. A rotenona leva à degeneração progressiva da via nigrostriatal e acúmulo da proteína alfa-sinucleina (125-127). Este sistema reproduz algumas características clínicas da Doença de Parkinson, como bradicinésia, rigidez dos membros, tremor e instabilidade postural (128). 


\subsection{Privação de sono}

A privação do sono REM foi realizada através do método da plataforma simples (129). Os animais foram colocados em uma plataforma circular $(6.5 \mathrm{~cm}$ de diâmetro) dentro de uma caixa $(23 \times 23 \times 30 \mathrm{~cm})$ preenchida com água até $1 \mathrm{~cm}$ de altura (medido a partir da base da caixa). No início de cada episódio de sono REM, o animal sofre perda do tônus muscular e cai na água, o que o mantem acordado, eliminando totalmente o sono REM (130). O grupo controle foi mantido na mesma sala dos animais em privação de sono durante todo o experimento. Os animais foram submetidos a um ciclo de privação do sono por $24 \mathrm{~h}$ horas, e, logo após este período, foram eutanasiados e as amostras coletadas.

\subsection{Coleta de tecidos para extração de RNA}

Os animais foram sedados com xilasina (10 mg/kg) e anestesiados com quetamina $(90 \mathrm{mg} / \mathrm{kg})$. Os cérebros foram dissecados para retirada das estruturas estudadas, Hipocampo, Hipotálamo, Estriado e Substancia Nigra, que foram imediatamente congeladas em nitrogênio líquido.

\subsection{Extração de RNA}

Para a extração de RNA do tecido, foi utilizado o método de extração e purificação de RNA por extração orgânica utilizando-se o reagente Trizol (Thermo Scientific, Wilmington, USA). A cada amostra, foi adicionado $1 \mathrm{~mL}$ de Trizol gelado e as amostras foram processadas utilizando-se o sonicador Politron (Analítica, São Paulo, Brasil). Posteriormente, adicionou-se 200 $\mu \mathrm{L}$ de clorofórmio e os lisados foram homogeneizados no vortex por 15s. As amostras foram centrifugadas por $30 \mathrm{~min}$ a $12.000 \mathrm{~g}$, a $4^{\circ} \mathrm{C}$, de forma a acelerar a separação de fases, e, posteriormente, a fase aquosa (translúcida) foi transferida para outro tubo, ao qual foram adicionados $500 \mu \mathrm{L}$ de Isopropanol para induzir a precipitação do RNA, o tubo eppendorf foi invertido delicadamente cinco vezes e incubado no gelo por $10 \mathrm{~min}$. Após este período, os tubos foram centrifugados por $15 \mathrm{~min}$ a $12.000 \mathrm{~g}$, a $4^{\circ} \mathrm{C}$. O sobrenadante foi removido e o pellet foi lavado com $1 \mathrm{~mL}$ de etanol $75 \%$ e centrifugado a $7.000 \mathrm{~g}$ por $5 \mathrm{~min}$, e o sobrenadante foi então descartado. O pellet foi lavado com $500 \mu \mathrm{L}$ de Etanol $75 \%$ e centrifugado 
a $7.000 \mathrm{~g}$ por $5 \mathrm{~min}$. O sobrenadante foi retirado e os tubos colocados na estufa a $65^{\circ} \mathrm{C}$ para evaporação do resíduo de etanol. Ao pellet seco, foram adicionados $50 \mu \mathrm{L}$ de $\mathrm{H}_{2} \mathrm{O}$ Milli-Q.

\subsubsection{Síntese de cDNA}

Os RNAs extraídos foram utilizados como molde para a síntese de cDNA, em reações de transcrição reversa. Alíquotas de $1 \mu \mathrm{g}$ de RNA total foram primeiramente incubadas por 10 min à $37^{\circ} \mathrm{C}$, com $2 \mu \mathrm{L}$ de DNase I $(1 \mathrm{U} / \mu \mathrm{L}$, Thermo Scientific), em solução contendo $2 \mu \mathrm{L}$ de tampão $5 x$ de síntese de primeira fita para a enzima Super Script III (Life Technologies) para todas as amostras e 0,5 $\mathrm{L}$ de RNase OUT TM (40U/ $\mu \mathrm{L}$, Thermo Scientific) em volume final de $10 \mu \mathrm{L}$. Posteriormente, esta enzima foi inativada por aquecimento à $75^{\circ} \mathrm{C}$ por $5 \mathrm{~min}$. A cada amostra de RNA previamente tratado, foram adicionados $1 \mu \mathrm{L}$ de Oligo dT $(0,5 \mu \mathrm{g} / \mu \mathrm{L}$, Thermo Scientific ) e $1 \mu \mathrm{L}$ de dNTP (10 mM, Thermo Scientific ), obtendo-se um volume final de reação de $12 \mu \mathrm{L}$. Em seguida, as amostras foram incubadas à $75^{\circ} \mathrm{C}$ por 10 minutos, para desnaturação das moléculas, e imediatamente colocadas no gelo. Adicionaram-se então $8 \mu \mathrm{L}$ de uma solução contendo $2 \mu \mathrm{L}$ de tampão $5 x$ de síntese de primeira fita para a enzima Super Script III (Thermo Scientific) suplementado com $\mathrm{MgCl}_{2}, 2 \mu \mathrm{L}$ de DTT $(0,1 \mathrm{M}$, Thermo Scientific), 0,5 $\mu \mathrm{L}$ de RNase OUT TM (40 U/ $\mu \mathrm{L}$, Thermo Scientific ), $1 \mu \mathrm{L}$ da enzima SuperScript TM III (200 U/ $\mu \mathrm{L}$, Life Technologies) e $2,5 \mu \mathrm{L}$ de água Milli-Q, para um volume final de reação de $20 \mu \mathrm{L}$. As reações foram incubadas à $25^{\circ} \mathrm{C}$ por 10 min, para anelamento dos primers e, posteriormente, à $45^{\circ} \mathrm{C}$ por $2 \mathrm{~h}$, para síntese dos cDNAs. Em seguida, a enzima transcriptase reversa foi inativada por meio da incubação das amostras à $72^{\circ} \mathrm{C}$ por $10 \mathrm{~min}$. Para a degradação das moléculas de RNA molde, adicionou-se $1 \mu \mathrm{L}$ de RNase $\mathrm{H}\left(5 \mathrm{U} / \mu \mathrm{L}\right.$, Fermentas - Thermo Scientific). As amostras foram incubadas à $37^{\circ} \mathrm{C}$ por $30 \mathrm{~min}$ e, posteriormente, à $72^{\circ} \mathrm{C}$ por $10 \mathrm{~min}$, para inativação da enzima. Posteriormente, as amostras foram diluídas 3 vezes em água Milli-Q.

\subsection{Desenho dos primers}

Os primers, ou oligonucleotídeos iniciadores, utilizados para a amplificação dos transcritos expressos nos experimentos de RT-PCR 
quantitativo, foram desenhados com o auxílio do software Primer-Blast (NCBI), no qual foram especificadas as opções: tamanho do produto do PCR entre 50150bp; conteúdo de CG entre 30 e 80\%, incapacidade de formação de dímeros ou de estrutura secundária, temperatura de anelamento entre $58^{\circ} \mathrm{C}$ e $60^{\circ} \mathrm{C}$, e organismo de interesse (Rattus norvegicus). Além disso, a fim de evitar uma eventual co-amplificação de DNA genômico contaminante, os pares de iniciadores foram desenhados em exons diferentes para cada um dos transcritos analisados. Os primers obtidos foram validados quanto à sua especificidade e características físico-químicas (como temperatura de anelamento e propensão à formação de dímeros ou estruturas secundárias) nas ferramentas Blat (UCSC University of California, Santa Cruz) OligoAnalyzer 3.1 (Integrated DNA Technologies), respectivamente. Os pares de primers utilizados neste estudo estão listados na Tabela 1.

Tabela 1: Sequência dos primers utilizados para quantificação da expressão gênica através de ensaios de RT-PCR quantitativo.

\begin{tabular}{|c|c|c|}
\hline \multirow{2}{*}{$\begin{array}{c}\text { Transcrito } \\
\text { Alvo }\end{array}$} & \multicolumn{2}{|l|}{ Lista de Primers } \\
\hline & Sequência & $\begin{array}{l}\text { Concentração } \\
\text { reacional (nM) }\end{array}$ \\
\hline B-actina & $\begin{array}{l}F>C G A G T A C A A C C T T C T T G C A G C \\
R>A T A C C C A C C A T C A C A C C C T G G\end{array}$ & 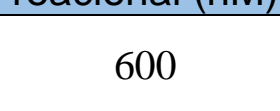 \\
\hline HPRT & $\begin{array}{c}F>C C C A G C G T C G T G A T T A G T G A \\
R>T G G C C T C C C A T C T C C T T C A T\end{array}$ & 600 \\
\hline Reck & $\begin{array}{l}F>C C C A G A T T A T T G C C C A G A G A C A \\
R>A C A C C T G G C A A A G A T G A G T T C A\end{array}$ & 800 \\
\hline Mmp-3 & $\begin{array}{l}\text { F TTCCTCTGAAACTTGGCGCA } \\
R>A C T T G A G G T T G A C T G G T G C C\end{array}$ & 800 \\
\hline Mmp-7 & $\begin{array}{l}F>T G A T G G G C C A G G A A A C A C T C \\
R>G T T C A C T C C T G A G T C C T C A C C\end{array}$ & 600 \\
\hline Mmp-9 & $\begin{array}{l}F>G C A T C T G T A T G G T C G T G G C T \\
R>T G C A G T G G G A C A C A T A G T G G\end{array}$ & 800 \\
\hline Timp-2 & $\begin{array}{c}F>A T G G C A A C C C C A T C A A G A G G \\
R>C C G C C T T C C C T G C A A T T A G A\end{array}$ & 800 \\
\hline GDNF & $\begin{array}{c}F>C A G A G G G A A A G G T C G C A G A G \\
R>A T C A G T T C C T C C T T G G T T T C G T A G\end{array}$ & 800 \\
\hline$N G F$ & $\begin{array}{c}F>A G C G C A T C G C T C T C C T T C A C \\
R>T T G G C A A A G C C T T T A T T G G G C\end{array}$ & 800 \\
\hline
\end{tabular}

F> indica a sequência do primer Foward; $\mathrm{R}>$ indica a sequência do primer reverse. 


\subsubsection{Determinação da concentração de uso dos primers}

A concentração de uso ideal de cada um dos pares de primers utilizados foi padronizada. Para isso, foram realizadas reações contendo primers em concentrações que variaram de 100 a $800 \mathrm{nM}$, e foi utilizado, como substrato, uma mistura dos $c D N A s$ das amostras dos tecidos analisados. A concentração ideal de cada primer foi determinada como sendo a menor concentração necessária para amplificação, sem que houvesse variação no valor de $\mathrm{Ct}$, além da mínima ou inexistente formação de dímeros.

\subsubsection{Determinação da eficiência dos primers}

Reações de amplificação, contendo primers na concentração ideal, determinada como citado acima, foram realizadas utilizando-se, como template, uma mistura de $c D N A s$ das amostras em diferentes concentrações (1:20, 1:30, 1:60, 1:120, 1:240). A análise de regressão linear dos valores de Cts em função do logaritmo da respectiva diluição do $c D N A$ forneceu o coeficiente angular da reta $(a$, em $y=a x+b)$ que foi utilizado para cálculo da eficiência de amplificação do produto pelos primers, na seguinte fórmula:

$$
E f=10^{-1 / \text { coeficiente angular }}
$$

$E f(\%)=(E f-1) \times 100$

\subsection{Reação de RT-PCR quantitativo}

Para permitir a quantificação do produto formado durante a reação de RTPCR quantitativo, utilizou-se o fluoróforo Fast SYBR® Green Master Mix (Thermo Scientific). Este reagente apresenta intensidade de emissão de fluorescência significativamente aumentada quando ligado à dupla fita de DNA. Dessa forma, quando livre em solução, o SYBR ${ }^{\text {TM }}$ Green Master Mix emite uma pequena fluorescência no comprimento de onda de $520 \mathrm{~nm}$. Entretanto, ao intercalar-se à dupla fita de DNA, devido à sua afinidade pelo sulco menor do DNA, tem-se um aumento de fluorescência da ordem de 100 vezes, permitindo 
a detecção do produto do qRT-PCR. Como substrato, foram utilizados $1,5 \mu \mathrm{L}$ do cDNA (sintetizado conforme descrito no item 3.7.1) diluído 20 vezes em água Milli-Q. Além disso, para cada uma das reações de RT-PCR quantitativo, adicionou-se 1,5 $\mu \mathrm{L}$ da mistura de primers (forward e reverse), na concentração de uso previamente determinada, e $3 \mu \mathrm{L}$ do reagente Fast SYBR® Green Master Mix. Todas estas reações de PCR foram realizadas em triplicata, no termociclador VIIA7 Real-Time PCR System (Applied Biosystems- Thermo Scientific). As condições das reações foram: 1 ciclo de 95ㄷ por 20seg; 40 ciclos de: $95^{\circ} \mathrm{C}$ por $1 \mathrm{seg}, 60^{\circ} \mathrm{C}$ por $20 \mathrm{seg}$; após a etapa de PCR, determina-se a curva de dissociação, a temperatura é elevada para 95ํㅡ por 15seg para desnaturação da fita dupla de DNA; em seguida, a temperatura é mantida à $60^{\circ} \mathrm{C}$ por $1 \mathrm{~min}$, seguido de uma elevação gradual da temperatura até $95^{\circ} \mathrm{C}$. Para $\mathrm{O}$ gerenciamento do termociclador e a coleta dos dados gerados durante a amplificação foi utilizado o programa computacional QuantStudio Real-Time PCR Software (Applied Biossystems).

Para cada amostra de $c D N A$, foram realizadas reações de RT-PCR utilizando-se primers para os genes-alvo e primers para genes de expressão endógena (nesse caso, Beta-Actina e HPRT). A expressão do gene-alvo foi determinada em função da expressão dos genes controles. Inicialmente, foi calculada a média dos Cts das triplicatas de cada amostra. A diferença entre as Medias dos Cts das amostras referências e a Média dos Cts de cada a amostra foi calculada, e esta diferença foi definida como $\Delta \mathrm{Cp}$.

A fórmula final (131) para o cálculo da diferença de expressão dos genes entre as amostras analisadas, que considera que não há um ganho de duas vezes do produto amplificado a cada ciclo, dado que a eficiência de amplificação dos primers utilizados não é de $100 \%$, é dada por:

$$
\text { ratio }=\frac{E f_{\text {gene alvo }}^{\Delta C P_{\text {genealvo }}}}{E f_{\text {controle endógeno }} \Delta C P_{\text {controle endógeno }}}
$$

Um fator de normalização foi gerado através do software geNorm, utilizando-se como genes de expressão endógena Beta-Actina e HPRT. 
Substituindo o divisor da equação anterior por esse fator de normalização, o resultado é o valor de expressão relativa de cada transcrito analisado.

\subsection{Western Blot}

\subsubsection{Obtenção de extratos protéicos}

As amostras das diferentes estruturas cerebrais foram coletadas e imediatamente congeladas. Para a extração adicionou-se duas vezes o volume da amostra de tecido de solução de lise (50 mM Tris $\mathrm{HCl} \mathrm{pH} \mathrm{7,5;} 5$ mM EDTA pH 8,0; $300 \mathrm{mM} \mathrm{NaCl}$ e 1\% NP-40) acrescido de inibidores de proteases específicos (GE HeathCare, Little Chalfont, Reino Unido). O sistema foi submetido à sonicação por 8 segundos (Sonicador SONICS Vibra Cell, SONICS, Newtown, CT, EUA). Posteriormente, o material foi mantido no gelo por 10 minutos e centrifugado a $20000 \mathrm{~g}$ por 10 minutos, para clarificação do sobrenadante por meio da retirada dos resíduos teciduais.

\subsubsection{Fracionamento de proteínas por eletroforese em gel de acrilamida e transferência para membrana de nitrocelulose}

A concentração das proteínas nos extratos foi determinada pelo método de Bradford (Kit Bio Rad, Hercules, CA, EUA), utilizando-se uma curva padrão de BSA (albumina sérica bovina). As amostras quantificadas foram submetidas ao fracionamento em gel vertical contendo de $10 \%$ poliacrilamida - SDS, à uma voltagem constante de $100 \mathrm{~V}$, durante aproximadamente 2 horas. Em seguida, as amostras fracionadas foram transferidas para membrana de nitrocelulose por transferência úmida (300 mA por 2 horas) em tampão de transferência ( $0,3 \%$ de Tris; $1,44 \%$ de glicina; $0,1 \%$ de SDS e $20 \%$ metanol).

\subsubsection{Imunoreação}

Para inibição da marcação de sítios inespecíficos, a membrana foi bloqueada com solução StartingBlock Blocking Buffer (Thermo Fisher Scientific), por 1 hora, à temperatura ambiente. Posteriormente, a membrana foi submetida a três lavagens com PBSAT, à temperatura ambiente, por 10 minutos. A incubação com o anticorpo primário de interesse, diluído adequadamente em 
solução de bloqueio, foi realizada à temperatura ambiente ou $4^{\circ} \mathrm{C}$, por 1 hora ou 16 horas, dependendo do anticorpo. A membrana foi lavada três vezes com PBSAT, à temperatura ambiente por 10 minutos, e, em seguida, esta foi incubada com $\mathrm{O}$ anticorpo secundário, anti-IgG conjugado com peroxidase (diluído em solução de bloqueio) à temperatura ambiente por 1 hora. $A$ membrana foi novamente lavada três vezes com PBSAT, por 10 minutos à temperatura ambiente. A marcação foi obtida utilizando-se o Kit Immobilon Western (Merk Millipore) para detecção de proteínas por quimioluminescência, seguindo-se as recomendações do fabricante. As imagens das bandas foram quantificadas por densitometria, por meio da utilização do programa computacional Image $(\mathrm{NIH})$.

\subsection{Análise estatística}

Para comparação de mais de duas populações de dados, foi realizada análise de variância one-way ANOVA, seguido do teste post-hoc Bonferroni. Todas as análises estatísticas foram realizadas utilizando-se o software GraphPad Prism 6 (GraphPad, CA, EUA). Os valores foram expressos como média mais o desvio padrão. As diferenças foram consideradas estatisticamente significativas quando $p<0,05$. 


\title{
4. Resultados
}

\section{Increased $M m p / R e c k$ expression ratio is associated to better recognition memory performance in a Parkinson's disease animal model}

\begin{abstract}
Parkinson's disease (PD) is the second most common neurodegenerative disorder worldwide. Among its non-motor symptoms, sleep disorders are extremely common and have been linked to cognitive and memory disruption. The microenvironment, in particular the extracellular matrix (ECM), is deeply involved in memory consolidation as well as in neuropathological processes such as inflammation, damage to the blood-brain barrier, and neuronal death. To better understand ECM dynamics in PD memory disturbances, we investigated the orchestrated expression of Mmps (Mmp-3, 7 and 9) and their modulators (Reck and Timp-3) in a rotenone-induced PD model. Also, we introduced an additional intervention in the memory process was introduced through rapid eye movement sleep deprivation (REMSD). REMSD reversed the rotenone induced cognitive impairment. Associated to this phenotype, we observed a significant increase in Mmp-7/Reck and Mmp-9/Reck mRNA expression ratio in the substantia nigra, and $M m p-9 / R e c k$ ratio in the hypothalamus. Moreover, the positive correlation of $\mathrm{Mmp} /$ Reck expression ratios between the substantia nigra and the striatum, observed upon rotenone infusion, was reversed by REMSD. Taken together, our results suggest a potential orchestrated association between an increase in Mmp-7 and $-9 /$ Reck expression ratios in the substantia nigra and a positive effect on cognitive performance in subjects affected by PD.
\end{abstract}

\section{Abbreviation list}

D1: Dopamine receptor 1

D2: Dopamine receptor 2

ECM: Extracellular matrix

GDNF: Glial cell derived neurotrophic factor

Mmp: Matrix metalloproteinase

MPTP: 1-methyl-4-phenyl-1,2,3,6-tetrahydropyridine

NGF: Nerve growth factor

PD: Parkinson's disease

Reck: REversion-inducing-Cysteine-rich protein with Kazal motifs

REM: Rapid eye movement

REMSD: REM sleep deprivation

SNpc: Substantia nigra pars compacta

\section{Introduction}

Parkinson's disease (PD) is the second most common neurodegenerative disorder worldwide (1). In 2015, approximately 6.2 million people were known to have the disease (2), and it is estimated that, by 2040, the number of diagnosed 
patients will exceed 12 million people (3). As most neurodegenerative diseases, its incidence correlates with age, rising sharply from age 65 (4). PD is characterized by the death of substantia nigra pars compacta dopaminergic neurons, leading to motor-signs, such as tremors, bradykinesia and stiffness (5). More recently, non-motor disturbances, such as sleep disturbances, memory impairment, olfactory dysfunction, mood disorders, depression, and anxiety, have also been related to the dopaminergic system (5). It is worth noting that rapid eye movement behavior disorder is among the early symptoms of this neurodegenerative disease and might precede its motor symptoms by several years (6). In fact, sleep disorders, such as insomnia, sleep fragmentation, and excessive daytime sleepiness, are extremely common and have been linked to cognitive and memory disruption in PD patients $(6,7)$.

The microenvironment, particularly the extracellular matrix (ECM), is site specific and acts as a modulator of brain physiology, playing a central role in processes, such as cellular differentiation, migration, inflammation, among others $(8,9)$. Therefore, the ECM is deeply involved in the development of central nervous system pathological conditions, such as PD $(10,11)$. Matrix Metalloproteinases (Mmps) are zinc-dependent enzymes, which are essential for ECM turnover (12). Therefore, it is not surprising that different Mmps, as well as their inhibitors, have been implicated in neuropathological processes, which are crucial for the development of PD through different mechanisms. Mmps may promote inflammation, cell death and damage to the blood-brain barrier, which can lead to hemorrhage and damage to the white matter and, also, angiogenesis and neurogenesis, which contribute to tissue repair $(13,14)$.

Moreover, these proteins are important for formation of new neural networks involving memory consolidation, learning, and cognition $(10,15,16)$. Particularly, Mmp-9 inhibition in vivo and Mmp-9 deficient mice display deficiencies in both long-term potentiation and memory consolidation (15,17-20). Additionally, the presence of the MMP-9 polymorphism $\mathrm{C}(-1562) \mathrm{T}$, which leads to its higher transcriptional expression, is associated with a higher PD risk (21). However, the role of Mmps and their inhibitors in the cognitive alterations observed in PD are still not clear.

The present study aims to investigate the potentially orchestrated expression of Mmps (Mmp-3, 7 and 9) and their modulators (Reck and Timp-3) in a PD animal model. Moreover, we introduced an additional, and potentially synergistic, intervention in the memory process through REM sleep deprivation, which was shown to impair the memory consolidation process $(22,23)$. To this end, adult Wistar rats were subjected to stereotaxic injection of rotenone, a well-known PD model (24), in addition (or not) to REMSD. The expression pattern of Mmps was determined in the hippocampus, hypothalamus, striatum, and substantia nigra. Animals submitted to rotenone injection alone presented a deficit in their cognitive performance. Interestingly, REMSD reversed the rotenone induced cognitive impairment. This improved cognitive performance was accompanied by higher expression ratios of $M m p-9 /$ Reck and $M m p-7 /$ Reck in the substantia nigra and lack of correlation of $\mathrm{Mmp} /$ Reck expression ratios between the substantia nigra and the striatum. A higher Mmp-9/ Reck expression ratio was also observed in the hypothalamus. Our results suggest that a higher Mmp/ Reck expression ratio, which might indicate a higher ECM remodeling status, particularly in the 
substantia nigra and hypothalamus, has a conceivable beneficial effect on cognitive performance in subjects affected by Parkinson's disease.

\section{Materials and Methods}

\section{Animal model}

For this study, male Wistar rats weighing between 280 and $320 \mathrm{~g}$, were used. All procedures were conducted in agreement with the guidelines of the Committee on the Care and Use of Laboratory Animals from the US National Institutes of Health (NIH, Bethesda, USA) and approved by Federal University of Paraná Ethics Committee (Process \#857). During the development of this study, the environmental surroundings were maintained at $22 \pm 2{ }^{\circ} \mathrm{C}$ and a $12 / 12 \mathrm{~h}$ light/dark cycle (with the light phase beginning at 7:00 a.m), and food and water being provided ad libitum.

\section{Experimental workflow}

PD was modeled through intranigral rotenone infusion, with an additional alteration in the animal's memory consolidation process being induced by REM sleep deprivation. The animals were distributed into four groups: (i) Sham Control, in which the animals were submitted to bilateral injection in the substantia nigra pars compacta (SNpc) of the vehicle dimethylsulfoxide (DMSO, SigmaAldrich, St. Louis, Missouri, EUA) alone and were not submitted to REM sleep deprivation; (ii) Rotenone Control, in which the animals were submitted to bilateral injection of rotenone in the SNpc but were not submitted to REM sleep deprivation; (iii) Sham REMSD, in which the animals were submitted to DMSO injection and were submitted to REM sleep deprivation; (iv) Rotenone REMSD, in which the animals were submitted to both rotenone injection and REM sleep deprivation. The stereotaxic procedures took place at day 0 and after recovering for seven days the animals were submitted (or not) to REM sleep deprivation for $24 \mathrm{~h}$. Subsequently, the animals were submitted to the object recognition test. The animals were euthanized, and the brain tissues were snap frozen and processed for RNA or protein extraction. Finally, gene expression analysis was performed by qRT-PCR and Western Blot (Fig. 1). 


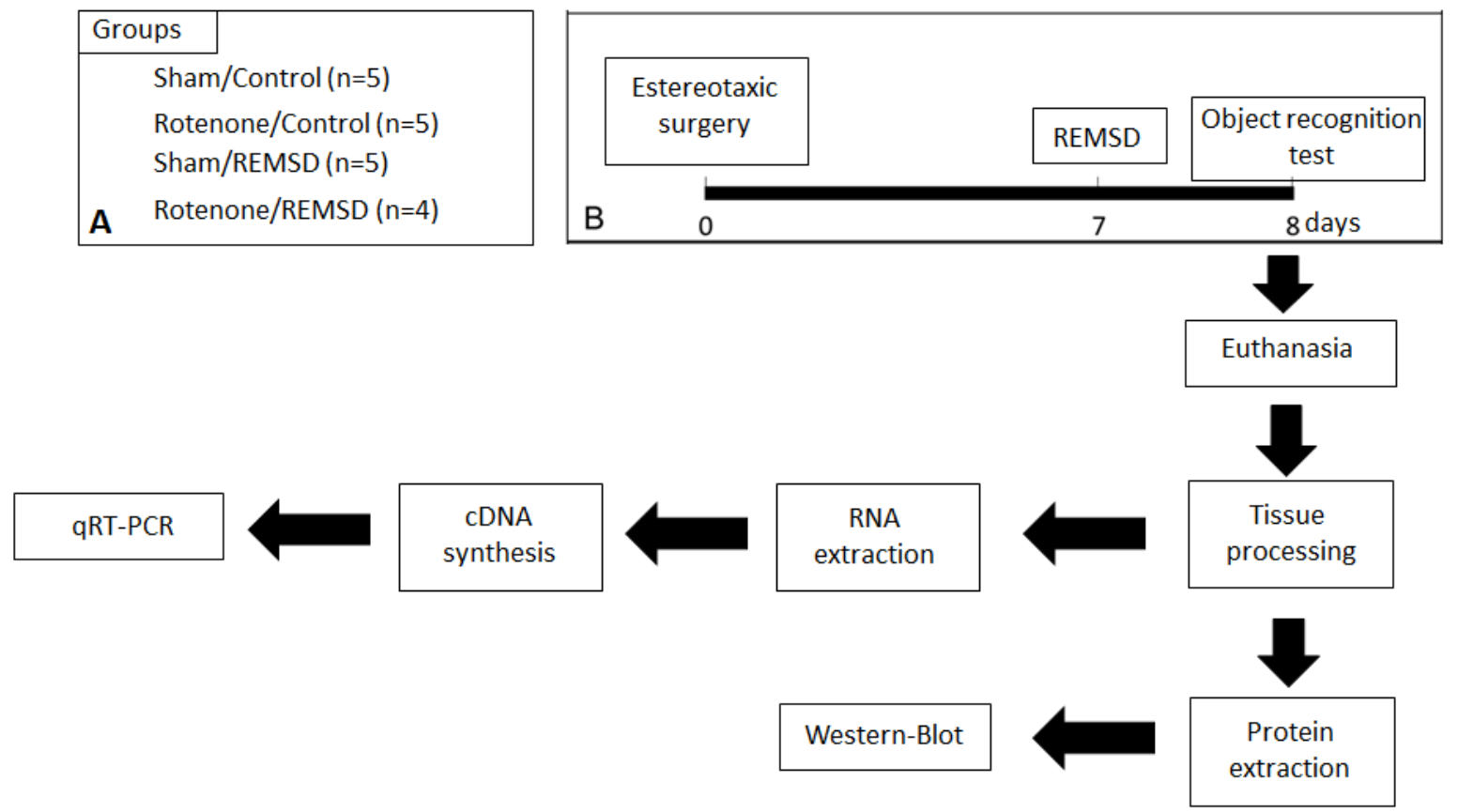

Figure 1. Experimental workflow. (A) The animals were divided into four experimental groups: sham/ control, rotenone/ control, sham/ REMSD, and sham/ REMSD. (B) Experimental workflow of the study: the stereotaxic infusion of rotenone or DMSO took place at day 0 and, after recovering for 7 days, the animals were submitted (or not) to REMSD for $24 \mathrm{~h}$, followed by the object recognition test. Next, the animals were euthanized, and the brain tissues were processed for downstream mRNA and protein expression assays.

\section{Stereotaxic surgery}

The animals were initially sedated with intraperitoneal xylazine $(10 \mathrm{mg} / \mathrm{kg}$; Syntec do Brasil Ltda, Brazil) and anesthetized with intraperitoneal ketamine $(90 \mathrm{mg} / \mathrm{kg}$; Syntec do Brasil Ltda, Brazil). Then, the animals were placed in the stereotaxic apparatus and an incision in the skin was made, making the skull and its sutures visible. From bregma, we localized SNpc, using the following coordinates: $(A P)=$ $-5.0 \mathrm{~mm},(\mathrm{ML})= \pm 2.1 \mathrm{~mm}$ and $(\mathrm{DV})=-8.0 \mathrm{~mm}(25) \mathrm{In}$ the sequence, rotenone (12 $\mu \mathrm{g} / \mathrm{\mu l}$; Sigma-Aldrich ${ }^{\circledR}$, United States) or DMSO 10\% v/v (Sigma-Aldrich ${ }^{\circledR}$, United States) infusions within SNpc were made at a rate of $0.33 \mu \mathrm{l} / \mathrm{min}$ during 3 minutes, totalizing $1 \mu \mathrm{l}$ in each hemisphere. These infusions were made using an electronic infusion pump (Insight Instruments, Ribeirão Preto, Brazil).

\section{REM sleep deprivation}

Animals were individually submitted to REM sleep deprivation (REMSD) by the single platform method, as previously described (26-28). In summary, each animal was placed in the apparatus, which is a cylindrical platform of $6.5 \mathrm{~cm}$ in diameter inside of a tank $(23 \times 23 \times 35 \mathrm{~cm})$, filled with water up to $1 \mathrm{~cm}$ below the platform surface, for 24 hours. Once the animal experiences a REM sleep episode, it loses its muscular tonus and falls into the water, being awakened. This process prevents the maintenance of REM sleep episodes (28). The control group, which was not sleep-deprived, was kept in a similar apparatus, in which the water was replaced by sawdust. Food and water were provided ad libitum within the grids localized at the top of the tanks. 


\section{Object recognition test}

The apparatus consists of an open box (width $x$ length $x$ height $=80 \mathrm{~cm} \times 80 \mathrm{~cm}$ $x 50 \mathrm{~cm}$ ) made of wood and covered with a black opaque plastic film. This test is based on the inner behavior of the animals to explore new things instead of familiar things. Thus, when an animal remembers a familiar object and does not know a new object, there is a tendency of this animal to explore the new object for a longer time when compared to the familiar object. The object recognition test in this study consisted of two phases: a sample/training phase and a choice/test phase. In the training phase, two identical objects were exposed in the back corners of the open box, $10 \mathrm{~cm}$ away from the sidewall. The rat was placed in the open box facing away from the objects and after 3 min of exploration, the rat was removed from the open box and returned to its cage. After a delay of $15 \mathrm{~min}$, the rat was reintroduced to the open box and the training phase was started again for further $3 \mathrm{~min}$. This situation was repeated for one more time. After REMSD, there was a training phase, followed by a test phase after an interval of $15 \mathrm{~min}$. In the test phase, two objects were presented in the same locations that were occupied by the previous sample objects. One of the objects was identical to the object seen in the training phase and the other one was different. The tests were video recorded, and we considered as exploration only when the rat touched the object with its nose or that rat's nose was directed toward an object at a distance $\leq 2 \mathrm{~cm}$.

\section{qRT-PCR}

Total RNA was isolated from frozen tissue samples through a phenol-based organic extraction method $\left(\right.$ Brazol $^{\circledR}$, Labdel, SP, Brazil). The corresponding cDNA was synthesized using the qPCRBIO kit (PCRBiosystems, London, UK). Amplification and detection of the target sequences and its detection were carried out using the Fast SYBR ${ }^{\circledR}$ Green master mix (Applied Biosystems, Foster City, USA) and the ViiA7 Real Time PCR System (Applied Biosystems), following the standard protocols recommended by the manufacturer. As a quality control for non-specific amplification or contamination, a dissociation cycle was performed after each run. Primers for the target genes (Reck, Mmp-3, -7, and -9, Timp-3, D1, D2, Gdnf and Ngf), and the endogenous control genes (Hprt and $\beta$-actin) were designed using PrimerBLAST, and validated through BLAT (sequences and final concentrations displayed in Supplementary Table 1). Expression ratios were calculated as described in (29), using the numerical factor generated by the geNorm program as the endogenous control normalization (30). Relative expression data were submitted to ANOVA one-way test followed by Tukey posthoc test. Heatmaps were generated using the Morpheus software (Broad Institute, Boston, USA).

\section{Western Blotting}

For protein extraction, the frozen tissue samples were sonicated (10 s pulse, $40 \%$ amplitude, SONICS Vibra Cell, SONICS, Newtown, USA) with $200 \mu \mathrm{L}$ of RIPA buffer ( $150 \mathrm{mM} \mathrm{NaCl}, 1 \% \mathrm{NP}-40,0.5 \%$ SDS, $50 \mathrm{mM}$ Tris pH8, $2 \mathrm{mM}$ EDTA). The tissue lysates were quantified by the Bradford protein assay (Bio-Rad, Hercules, USA) according to the manufacturer's instructions. Protein extracts $(100 \mu \mathrm{g})$ were resolved on a $12 \%$ SDS-Page gel and transferred to a nitrocellulose membrane. 
The membranes were blocked for one hour in StartingBlock solution (ThermoFisher Scientific, Thermo Scientific, Wilmington, USA), followed by incubation for $16 \mathrm{~h}$ at $40 \mathrm{C}$ with either the anti-RECK antibody (1: 2000, Cat \#3433, Cell Signaling, Danvers, USA), Anti-MMP-9 antibody (1: 2000, Cat\# ab76003, Abcam, Cambridge, UK), or anti-Tubulin (1: 5000, Cat\# ab56676, Abcam). The membranes were thoroughly washed with PBST and then incubated for $1 \mathrm{~h}$ with anti-rabbit antibody (1: 2000, Cat \#a4914, Sigma-Aldrich, St. Louis, Missouri, USA) or anti-mouse antibody (1: 2000, Cat\# a4416, SigmaAldrich) diluted in StartingBlock solution. Following the PBS washes, the peroxidase signal was obtained using the Clarity Western ECL Substrate (BioRad, Hercules, USA) and detected using Image Quant LAS 4000 mini (GE, Boston,USA). Densitometry and quantification of the bands was carried out using the Image J software $(\mathrm{NIH})$ and the relative expressions ratios of Reck and Mmp9 were determined through normalization relative to Tubulin expression. Relative expression data were submitted to ANOVA one-way test followed by Tukey posthoc test.

\section{Statistical Analysis}

The normal distribution of the data was assessed by the Kolmogorov-Smirnov test. Comparisons of the total exploration time in the object recognition test between the experimental groups were carried out using repeated measures twoway ANOVA followed by Fisher LSD test. Relative mRNA and protein expression comparisons were carried out using one-way ANOVA followed by Tukey posthoc test. The Pearson test was used for gene expression correlation analysis. All statistical analyses were carried out using the Graph Pad Prism 5 software. The results are presented as the mean with error bars standing for the standard error of the mean. A p-value of less than 0.05 was considered as statistically significant.

\section{$3 \quad$ Results}

Aiming to evaluate the cognitive performance in the rotenone PD model, we performed the object recognition test (Fig. 2). We observed that the sham group spent more time exploring the new object, compared to the time exploring the familiar object ( $p \leq 0.01)$. Differently, rotenone infusion led to memory impairment, demonstrated by a similar time exploring both objects $(\mathrm{p}=0.72)$, an impairment reversed by REMSD $(p \leq 0.05)$. 


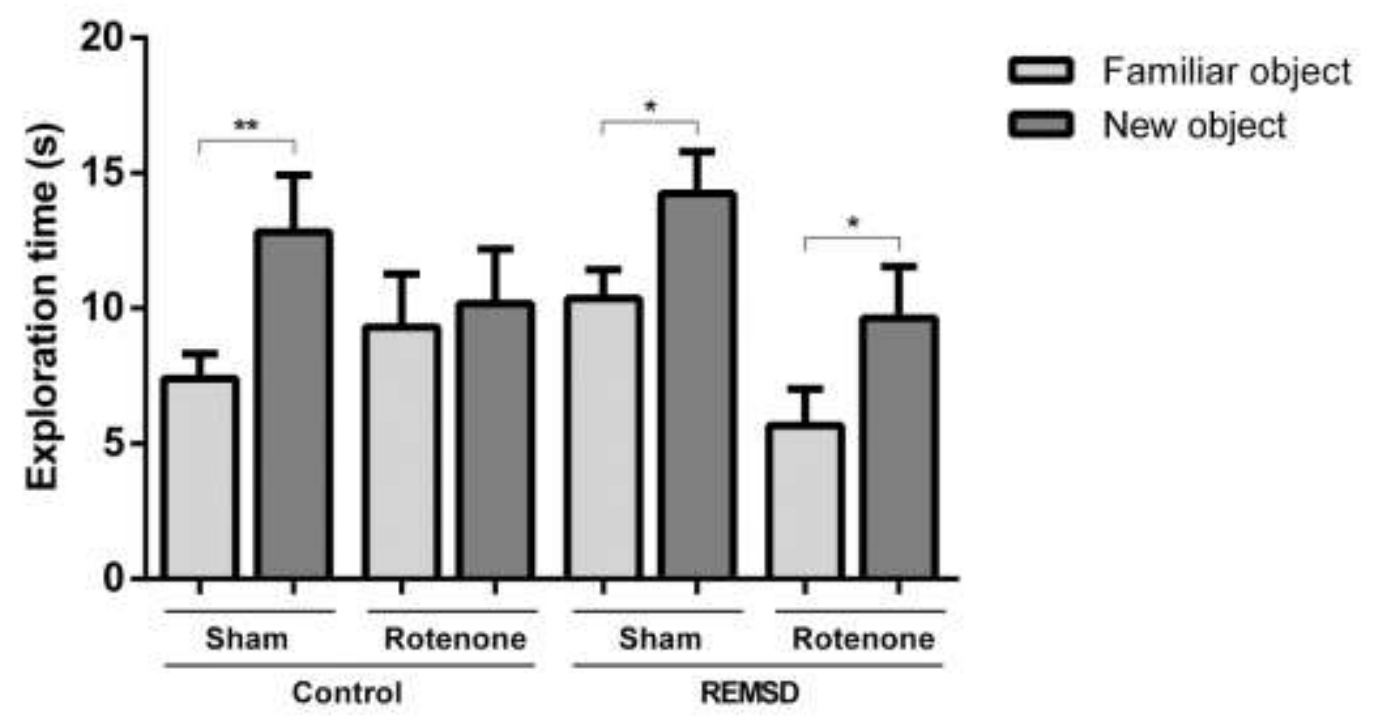

Figure 2. Performance in the object recognition test upon rotenone infusion and/or REM sleep deprivation. Columns represent total exploration time \pm standard error of mean $(n=8$ to 12). Statistical analysis was carried out using repeated measures two-way ANOVA followed by Fisher LSD test. ${ }^{* *}$ stands for $p \leq 0.01$, and ${ }^{*}$ for $p \leq 0.05$.

Investigation of the combined expression of $M m p-3,7$ and 9, their inhibitors Reck and Timp-3 and the neural growth factor Gdnf and Ngf in different brain structures (hippocampus, hypothalamus, striatum, and substantia nigra) was carried out through qRT-PCR. In order to further explore the dynamics of the Mmp9/ Reck expression ratio in this model, their protein expression was determined by Western Blotting.

\section{Hippocampus}

None of the target genes displayed statistically significant modulation of their corresponding RNA (Fig. 3a, Supplementary Fig. 1) or protein (Fig. 3d, e, and f) expression levels upon rotenone infusion and/or REMSD. Nor did Mmp-9/ Reck and Mmp-7/Reck expression ratios showed any alteration (Fig. 3b, c, and g). In this structure, Mmp-3, 7 and 9 expression levels positively correlated with each other, and Mmp-7 expression also correlated with Timp3 expression (Fig. 3a, Supplementary Fig.1, Table 1). 
Table 1 Pearson's correlation test between the target genes relative mRNA expression levels in different brain structures

\begin{tabular}{|c|c|c|c|c|c|c|c|c|c|c|c|c|c|}
\hline & & \multicolumn{3}{|c|}{ Hippocampus } & \multicolumn{3}{|c|}{ Hypothalamus } & \multicolumn{3}{|c|}{ Striatum } & \multicolumn{3}{|c|}{ Substantia Nigra } \\
\hline & & Reck & \begin{tabular}{|c|}
$M m p-$ \\
7 \\
\end{tabular} & \begin{tabular}{|c|}
$M m p-$ \\
9 \\
\end{tabular} & Reck & \begin{tabular}{|c|}
$M m p-$ \\
7 \\
\end{tabular} & $\begin{array}{c}M m p- \\
9 \\
\end{array}$ & Reck & $\begin{array}{c}\text { Mmp- } \\
7 \\
\end{array}$ & $\begin{array}{c}\text { Mmp- } \\
9 \\
\end{array}$ & Reck & $\begin{array}{c}M m p- \\
7 \\
\end{array}$ & $\begin{array}{c}M m p- \\
9 \\
\end{array}$ \\
\hline \multirow{2}{*}{ Reck } & $r$ & & -0.423 & -0.302 & & 0.145 & 0.545 & & -0.210 & -0.111 & & -0.443 & -0.250 \\
\hline & $p$ & & 0.149 & 0.316 & & 0.593 & 0.029 & & 0.472 & 0.707 & & 0.058 & 0.302 \\
\hline \multirow{2}{*}{$M m p-3$} & $r$ & -0.470 & 0.802 & 0.676 & 0.274 & 0.758 & 0.893 & 0.220 & 0.535 & 0.710 & -0.512 & 0.494 & 0.412 \\
\hline & $p$ & 0.105 & 0.001 & 0.011 & 0.304 & 0.001 & 0.000 & 0.450 & 0.049 & 0.004 & 0.025 & 0.032 & 0.079 \\
\hline \multirow{2}{*}{$M m p-7$} & $r$ & -0.423 & & 0.735 & 0.145 & & 0.706 & -0.210 & & 0.723 & -0.443 & & 0.782 \\
\hline & $p$ & 0.149 & & 0.004 & 0.593 & & 0.002 & 0.472 & & 0.003 & 0.058 & & 0.000 \\
\hline \multirow{2}{*}{$M m p-9$} & $r$ & -0.302 & 0.735 & & 0.545 & 0.706 & & -0.111 & 0.723 & & -0.250 & 0.782 & \\
\hline & $p$ & 0.316 & 0.004 & & 0.029 & 0.002 & & 0.707 & 0.003 & & 0.302 & 0.000 & \\
\hline \multirow{2}{*}{ Timp-3 } & $r$ & -0.408 & 0.756 & 0.549 & 0.449 & 0.507 & 0.483 & -0.217 & 0.350 & 0.539 & -0.184 & 0.880 & 0.798 \\
\hline & $p$ & 0.166 & 0.003 & 0.052 & 0.081 & 0.045 & 0.058 & 0.457 & 0.220 & 0.047 & 0.450 & 0.000 & 0.000 \\
\hline \multirow{2}{*}{ Ngf } & $r$ & -0.364 & -0.091 & -0.131 & 0.268 & 0.744 & 0.816 & 0.165 & 0.481 & 0.774 & -0.089 & 0.621 & 0.541 \\
\hline & $p$ & 0.222 & 0.767 & 0.671 & 0.316 & 0.001 & 0.000 & 0.573 & 0.082 & 0.001 & 0.717 & 0.005 & 0.017 \\
\hline \multirow{2}{*}{ Gdnf } & $r$ & 0.272 & 0.003 & -0.052 & 0.332 & 0.947 & 0.826 & -0.282 & 0.822 & 0.656 & -0.194 & 0.870 & 0.821 \\
\hline & $p$ & 0.369 & 0.992 & 0.866 & 0.208 & 0.000 & 0.000 & 0.329 & 0.000 & 0.011 & 0.427 & 0.000 & 0.000 \\
\hline \multirow{2}{*}{$D 2$} & $r$ & -0.040 & -0.037 & 0.375 & 0.431 & 0.803 & 0.639 & -0.071 & 0.195 & -0.138 & 0.015 & 0.722 & 0.689 \\
\hline & $p$ & 0.897 & 0.904 & 0.207 & 0.095 & 0.000 & 0.008 & 0.808 & 0.505 & 0.639 & 0.952 & 0.000 & 0.001 \\
\hline & $r$ & -0.022 & 0.067 & 0.408 & 0.209 & 0.962 & 0.798 & 0.105 & 0.636 & 0.594 & -0.196 & 0.848 & 0.801 \\
\hline & $p$ & 0.942 & 0.829 & 0.167 & 0.438 & 0.000 & 0.000 & 0.720 & 0.015 & 0.025 & 0.420 & 0.000 & 0.000 \\
\hline
\end{tabular}

in bold: $0.7<r<1$ and $p<0.05$. 
a.

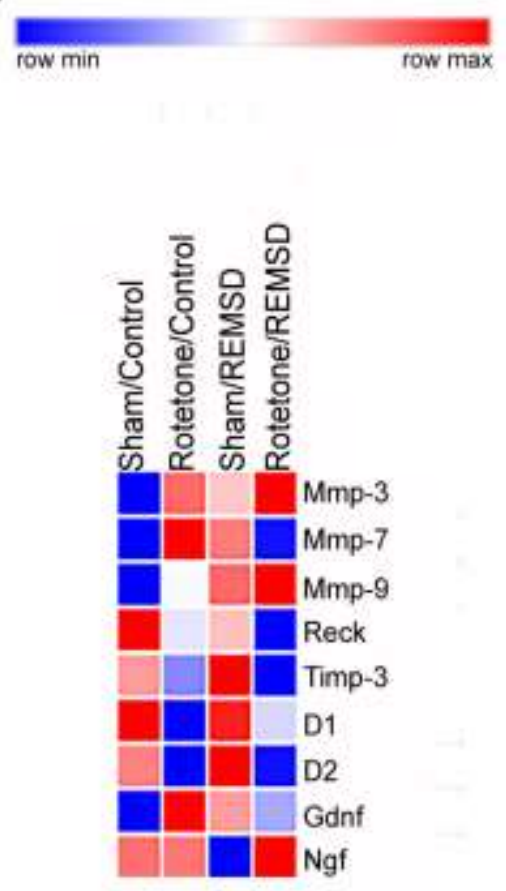

b.

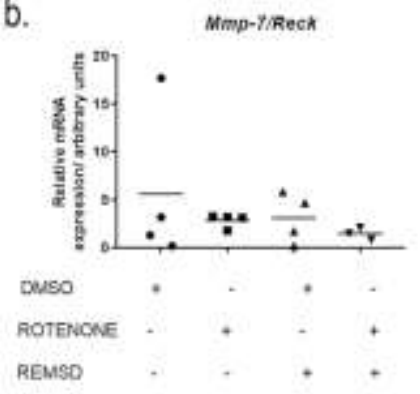

d.

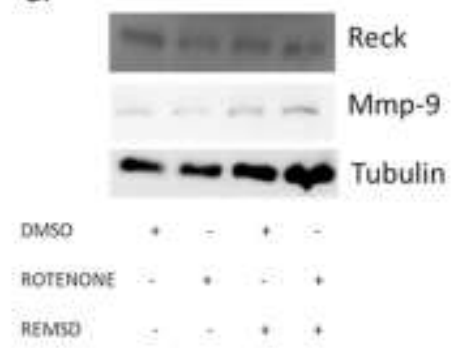

f.

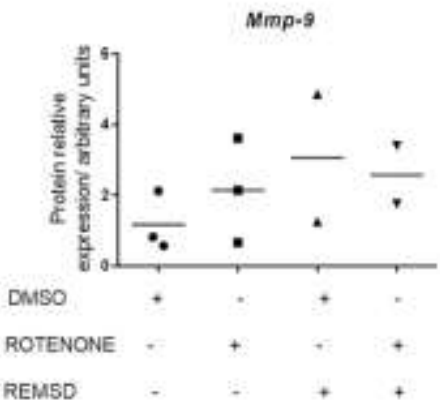

C.

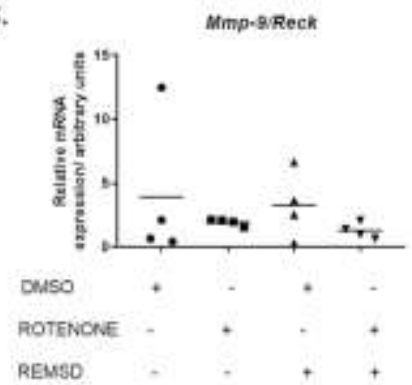

e.

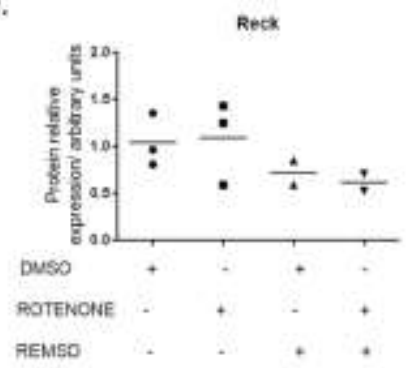

g.

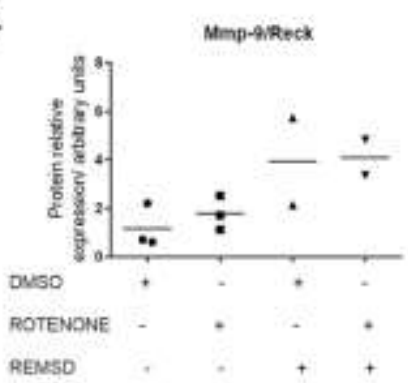

Figure 3 Expression profile in the Hippocampus upon rotenone infusion and/or REM sleep deprivation. a. Heatmap of the mRNA expression profiles of Mmp3, 7, 9. Reck, Timp-3, D1, D2, GDNF and NGF determined by qRT-PCR ( $\mathrm{n}=3$ to 5 for each group); b. Mmp-7/Reck and c. Mmp9/Reck mRNA expression ratios; d. Representative image of the Western Blotting results; e. Mmp9 protein and f. Reck protein expression profiles determined by Western Blotting ( $n=2$ to 3 for each group); f. Mmp-9/Reck protein expression ratio. Expression data were submitted to one-way ANOVA followed by Tukey post-hoc test.

\section{Hypothalamus}

Although no individual target gene displayed statistically significant modulation of their RNA (Figure 4a, Supplementary Fig. 2) or protein (Fig. 4d, e, and f) expression levels, the ratio of $M m p-9 /$ Reck (Figure 4c), but not of $M m p-7 /$ Reck (Fig. 4b) expression was modulated under the conditions utilized. The Mmp-9/ Reck mRNA expression ratio was higher in the hypothalamus of animals submitted to both rotenone infusion and REMSD ( $p \leq 0.05$ ), when compared to the animals separately submitted to each of these conditions. The Mmp-9/ Reck protein expression ratio (Fig. $4 \mathrm{~g}$ ) did not display a statistically significant modulation but followed the same trend as the mRNA expression. The mRNA expression levels of Mmps correlated not only among each other, but, also, with those of Ngf, Gdnf and dopamine D1 (D1) and D2 (D2) receptors (Fig. 4a, Supplementary Fig.2 Table 1). 
a.

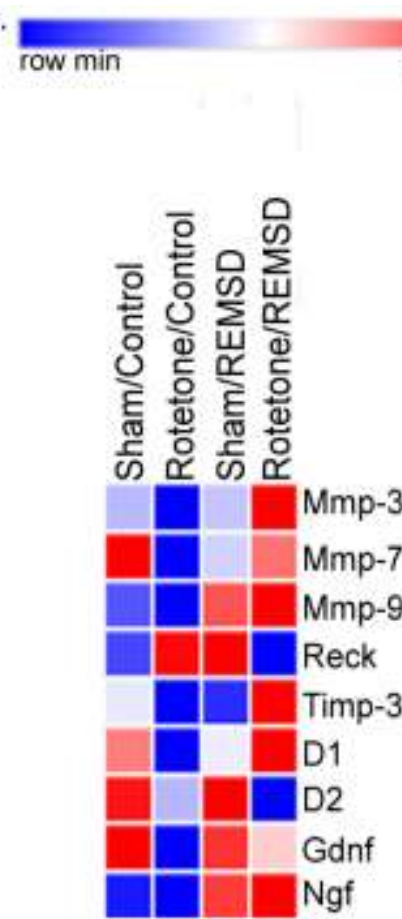

b.

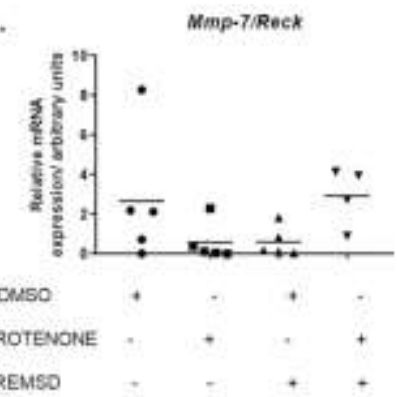

d.

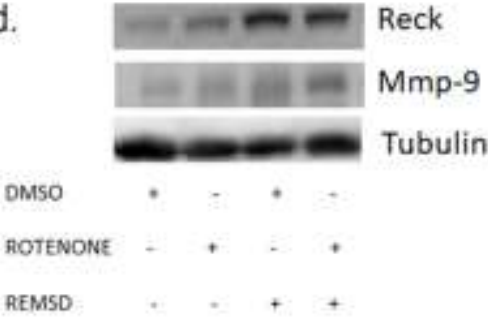

f.

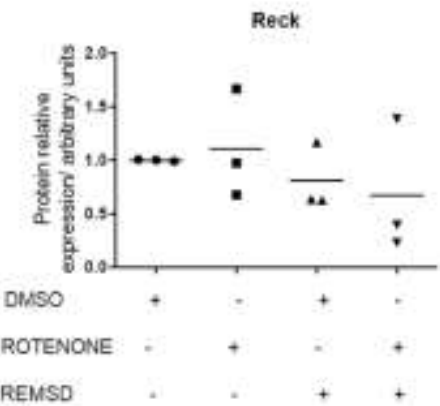

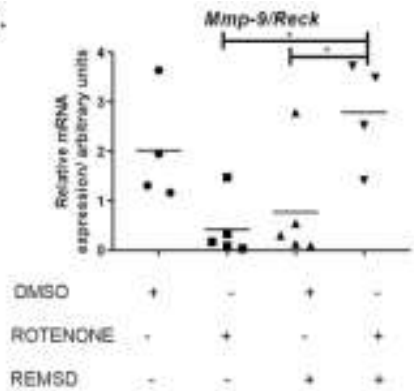

e.

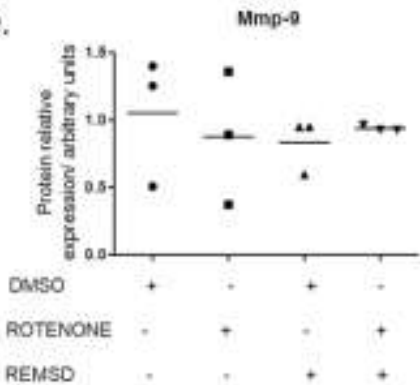

g.

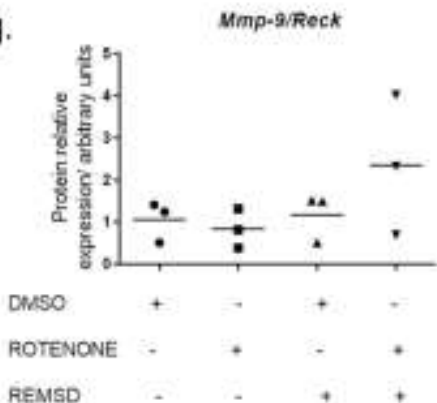

Figure 4 Expression profile in the Hypothalamus upon rotenone infusion and/or REM sleep deprivation. a. Heatmap of the mRNA expression profiles of Mmp-3, 7, 9. Reck, Timp-3, D1, D2, GDNF and NGF determined by qRT-PCR ( $\mathrm{n}=3$ to 5 for each group); b. Mmp-7/Reck and c. Mmp9/Reck mRNA expression ratios; d. Representative image of the Western Blotting results; e. Mmp9 protein; and f. Reck protein expression profiles determined by Western Blotting $(n=3$ for each group); g. Mmp-9/Reck protein expression ratio. Expression data were submitted to one-way ANOVA followed by Tukey post-hoc test. ${ }^{*}$ stands for $p \leq 0.05$.

\section{Striatum}

Analysis of the expression profiles of the target genes (Fig. 5a, d, e and $f$, Supplementary Fig. 3) indicated that Mmp-9 (Fig. 5a and e) displayed a significant increase when the animals were submitted solely to REMSD ( $\leq \leq 0.05)$. This pattern was also observed for the Mmp-9/Reck (Fig. 5c and g) and Mmp-7/ Reck (Fig. 5b) expression ratios ( $p \leq 0.05$ ). As in the former structures analyzed, Mmps mRNA expression levels correlated among each other (Table 1). In addition, a positive correlation was found between Mmp-7 and Gdnf expression levels and between Mmp-9 and Ngf expression levels (Fig. 5a, Supplementary Fig. 3, Table 1). 
a.

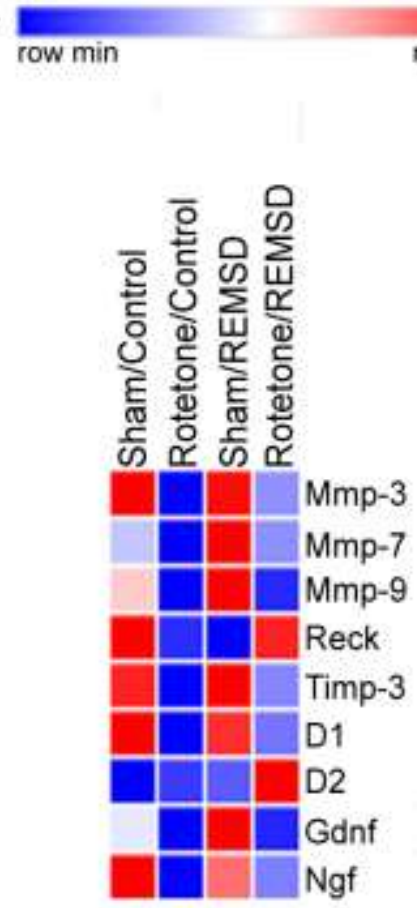

b.

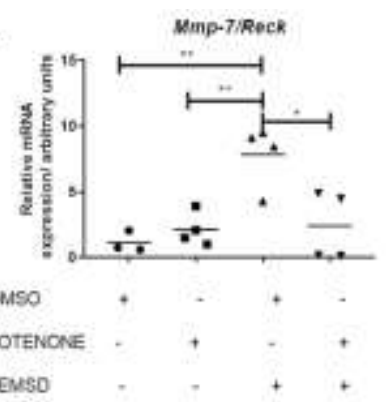

d.

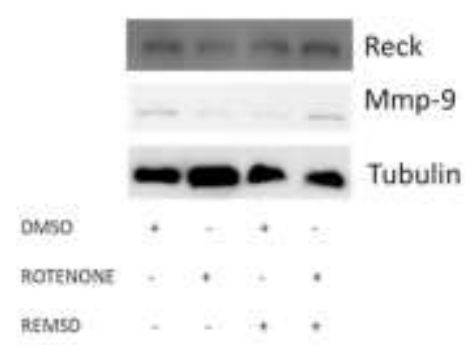

f.

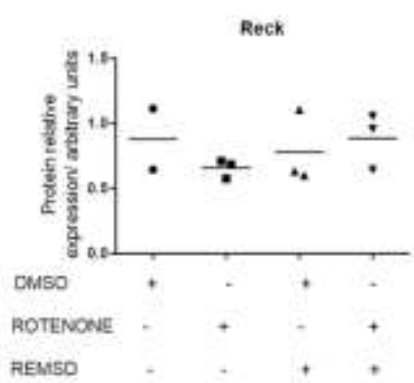

C.

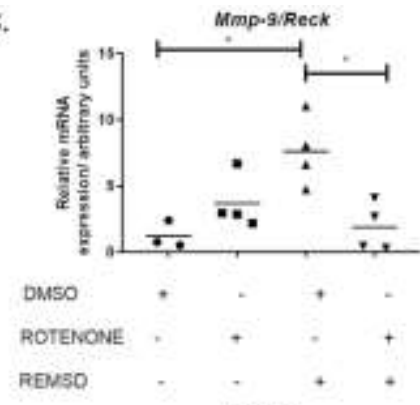

e.

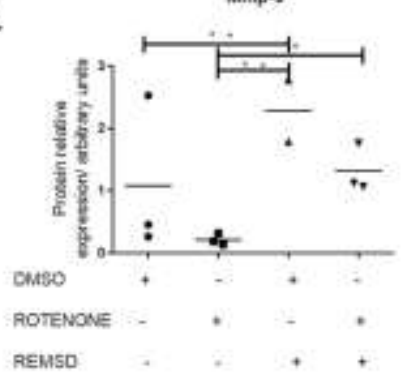

g.

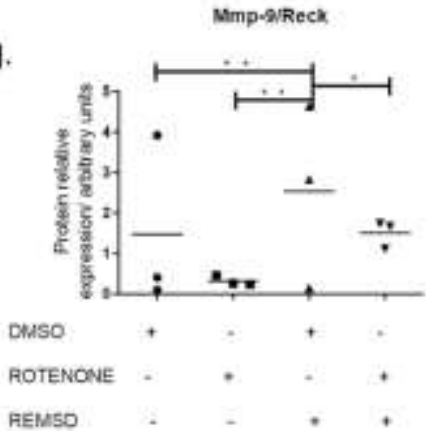

Figure 5 Expression profile in the Striatum upon rotenone infusion and/or REM sleep deprivation. a. Heatmap of the mRNA expression profiles of Mmp-3, 7, 9. Reck, Timp-3, D1, D2, GDNF and NGF determined by qRT-PCR ( $\mathrm{n}=3$ to 5 for each group); b. Mmp-7/ Reck and c. Mmp-9/ Reck mRNA expression ratios; d. Representative image of the western blot results; e. Mmp-9 protein and f. Reck protein expression profiles determined by Western Blotting ( $n=2$ to 3 for each group); g. Mmp-9/ Reck protein expression ratio. Expression data were submitted to oneway ANOVA followed by Tukey post-hoc test. * stands for $p \leq 0.05$ and ${ }^{* *}$ for $p \leq 0.01$.

\section{Substantia Nigra}

Even though none of the target genes displayed statistically significant modulation of their RNA (Fig. 6a, Supplementary Fig. 4) or protein (Fig. 3d, and e) expression levels, both Mmp-7/ Reck ( $\leq 0.01$, Fig. 6b) and Mmp-9/ Reck $(p \leq 0.05$, Fig. 6c) mRNA expression ratios increased upon REMSD in rotenone infused animals. Interestingly, Mmp-9 protein expression was not detectable by Western Blotting (data not shown), which might be explained by its low expression in this structure. Both $M m p 7$ and $9 \mathrm{mRNA}$ expression levels positively correlated between each other, and, also, with Timp-3, Gdnf, Ngf, D1 and D2 expression levels (Fig. 6a,Supplementary Fig. 4, Table 1). 
a.

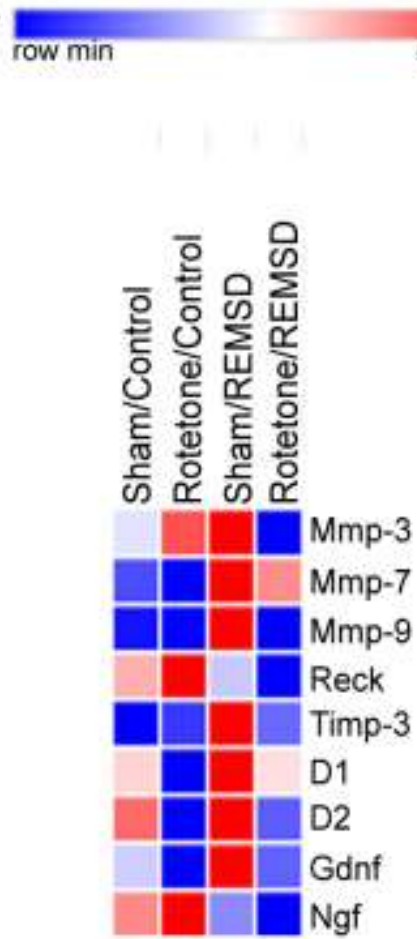

b.

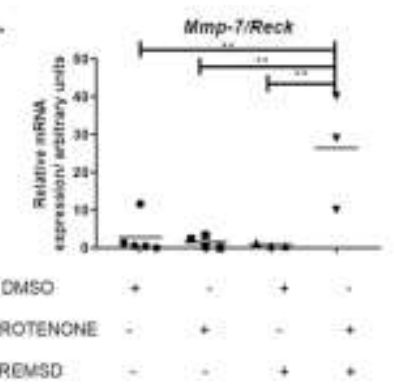

d.

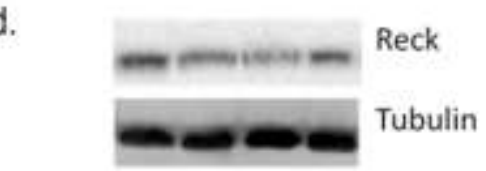

DMso

ROTENONE

REMSD
C.

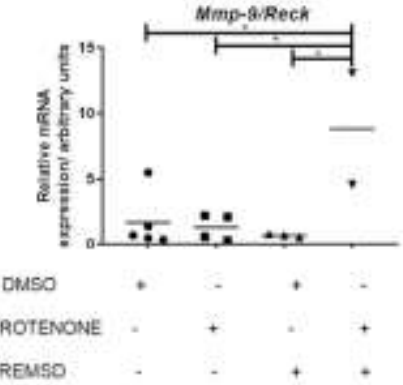

e.

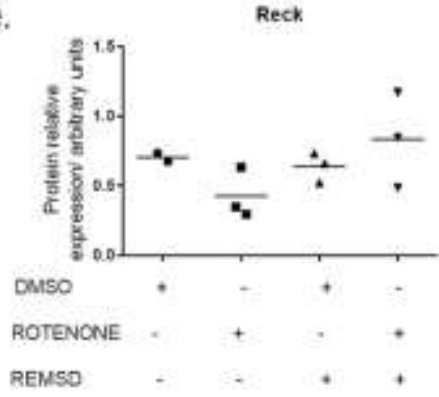

Figure 6 Expression profile in the Substantia Nigra upon rotenone infusion and/or REM sleep deprivation. a. Heatmap of the mRNA expression profiles of Mmp-3, 7, 9. Reck, Timp-3, $D 1, D 2, G D N F$ and NGF determined by qRT-PCR ( $\mathrm{n}=3$ to 5 for each group); b. Mmp-7/Reck and c. Mmp-9/Reck mRNA expression ratios; d. Representative image of the Western Blotting results; e. Reck protein expression profile determined by Western Blotting ( $n=2$ to 3 for each group). Expression data were submitted to one-way ANOVA followed by Tukey post-hoc test. *stands for $p \leq 0.05$ and ${ }^{* *}$ for $p \leq 0.01$.

Table 2 Pearson's correlation test of Mmp-7/Reck and Mmp-9/Reck mRNA expression ratios in the SNpc versus in the Striatum

\begin{tabular}{|c|c|c|c|}
\hline \multirow[b]{2}{*}{ Groups } & & \multicolumn{2}{|c|}{ Correlations } \\
\hline & & $\begin{array}{l}\text { Mmp-7/Reck ratio } \\
\text { SNpc x striatum }\end{array}$ & $\begin{array}{c}\text { Mmp-9/Reck ratio } \\
\text { SNpc x striatum }\end{array}$ \\
\hline \multirow[t]{2}{*}{ Sham control } & $r$ & 0.73 & -0.73 \\
\hline & $\mathrm{p}$ & 0.48 & 0.48 \\
\hline \multirow{2}{*}{$\begin{array}{l}\text { Rotenone } \\
\text { control }\end{array}$} & $r$ & 0.98 & 0.96 \\
\hline & $p$ & 0.02 & 0.03 \\
\hline \multirow[t]{2}{*}{ Sham REMSD } & $r$ & -0.42 & -0.54 \\
\hline & $p$ & 0.48 & 0.35 \\
\hline \multirow{2}{*}{$\begin{array}{l}\text { Rotenone } \\
\text { REMSD }\end{array}$} & $r$ & -0.08 & -0.17 \\
\hline & $p$ & 0.92 & 0.83 \\
\hline
\end{tabular}

Significant correlations are indicated in bold. Substantia nigra pars compacta (SNpc); REM sleep deprived (REMSD). 


\section{$M m p / R e c k$ expression ratios in the SNpc versus in the Striatum}

Considering the relevance of the nigrostriatal axis to PD and REM sleep regulation, the correlation between Mmp/ Reck expression ratios in the SNpc and striatum was investigated. Both Mmp-7/ Reck and Mmp-9/ Reck mRNA expression ratios positively correlated in the Rotenone control group $(p \leq 0.05)$ (Table 2).

\section{Discussion}

Rotenone exposure, as well as REMSD, is detrimental to the memory consolidation process $(22,23,27,31,32)$. Memory consolidation is associated to changes in the strength and structure of synaptic connections, as well as to remodeling of the surrounding ECM (33). Mmp family members are crucial for ECM turnover, which is evidenced by the fact that stereotaxic injection of a broad spectrum Mmp-2/9 inhibitor, FN-439, in the lateral ventricle of rats, resulted in disruption of fear memory reconsolidation (17). Considering Mmps' role in memory consolidation and the memory impairment caused by rotenone exposure, we introduced a REMSD step in the experimental workflow as a potentially deleterious synergistic agent upon memory consolidation and evaluated the balance between the expression levels of Mmp-7 and 9, and of their inhibitor Reck.

Remarkably, the animals submitted to rotenone exposure and subsequent REMSD did not display the cognitive deficit observed in the animals which received rotenone only. A similar result was observed previously, in which this absence of memory impairment was associated with a lack of decreased dopamine levels within the striatum $(31,34-36)$. Furthermore, our data indicate that the balance between Mmps and Reck expression displays a brain structuredependent modulation in this model.

The hippocampus is a structure related to learning and memory consolidation $(37,38)$. Moreover, the hippocampus is a neurogenesis site in the adult brain, and a considerable reduction of its volume is observed during PD progression $(39,40)$. Studies in rats demonstrated an increase in Mmp-9 activity in the hippocampus, which reached its peak five days after submission of the animals to the Morris water maze $(41,42)$. Mizogushi et al. demonstrated that $M m p-9$ knockout mice present deficits in the object recognition task, while their performance in the $\mathrm{Y}$ maze remains normal $(19,43)$. These results suggest that $M m p-9$ plays a critical role in synaptic plasticity and hippocampal-dependent memory (43). In our model, no statistically significant modulation in Mmp-7, -9 or Reck expression levels was observed upon rotenone infusion or REMSD in the hippocampus, which might be explained by differences in the specific protocols utilized or in the time intervals evaluated. Further studies, analyzing different periods after the object recognition test performance, would be necessary to better clarify the action of Mmps and Reck in the hippocampus of PD affected animals upon a learning stimulus.

The sleep influence on memory consolidation is widely explored in the literature $(44,45)$. Regulation of the sleep/wake cycle is a complex mechanism involving several brain structures and neurotransmitters, such as the substance nigra (46) and the hypothalamus (47). The hypothalamus has specialized neural sub- 
populations: neurons located on the posterior region are involved in maintenance of the sleep/ wake cycle integrity, while the ones on the pre-optic region are involved in maintenance of the sleep state (48). Interestingly, although neither rotenone infusion nor REMSD alone, significantly modified $\mathrm{Mmp}-7$ or -9 and Reck expression balance in the hypothalamus, we observed an increase in the Mmp9/Reck mRNA expression ratio concomitant to an increase in cognition in the rotenone REMSD group, suggesting a higher ECM remodeling status under this condition.

We also analyzed the correlation between the expression of $M m p-7,-9$ and the neurotrophic factors $\mathrm{Ngf}$ and Gdnf, as well as the dopamine receptors $D 1$ and D2. Ngf induces neuronal outgrowth and promotes survival and maintenance of sensory and sympathetic neurons derived from the neural crest, as well as of the central cholinergic neurons of the basal forebrain $(49,50)$. The serum levels of Ngf were found to be reduced in rats with PD, compared to control animals, as well as in those patients at early stages of the disease (51). Moreover, Ngf has a protective effect in dopaminergic PC12 cells exposed to 6-hydroxydopamine, preventing the accumulation of reactive oxygen species (52). Gdnf is an important factor for the development, maintenance, and protection of the nigrostriatal dopaminergic neurons, having a potential therapeutic use in PD $(53,54)$. Remarkably, both Mmp-7 and -9 mRNA expression levels in the hypothalamus positively correlated with the expression levels of $\mathrm{Ngf}$, Gdnf and the dopamine receptors $D 1$ and $D 2$, suggesting that these Mmps might be associated to a protective phenotype in PD.

Annese et al. observed that $24 \mathrm{~h}$ after MPTP intraperitoneal injection, there is an increase in Mmp-9 mRNA expression in the SNpc (55). In the present study, we analyzed $M m p-9$ and $M m p-7$ mRNA expression levels and their ratios, relative to the expression of their inhibitor Reck, after seven days of rotenone infusion. No significant modulation of these Mmps or their ratios was observed, suggesting that such modulation is an early event after the induction of the lesion in the SNpc. Remarkably, we observed that, after REMSD, animals exposed to rotenone presented a significant increase in Mmp-7/Reck and Mmp-9/Reck mRNA expression ratios in the $\mathrm{SNpc}$, suggesting that $\mathrm{Mmp}$ remodeling might be important in this model, however, further studies are required to clarify the role of individual Mmps in this process.

PD modeling through 1-methyl-4-phenyl-1,2,3,6-tetrahydropyridine neurotoxin (MPTP) administration led to a striatal increase in Mmp-9 enzymatic activity $1 \mathrm{~h}$ after MPTP exposure, with its peak occurring after $3 \mathrm{~h}$, returning to basal levels immediately after that (56). We did not observe any Mmp-9 modulation upon rotenone exposure in the striatum 8 days after the procedure. We speculate that this alteration in Mmp-9 activity might consist of an early striatal response mechanism, triggered by the exposure to the compounds.

Furthermore, the nigrostriatal neurons actively participate in the REM sleep regulation (57). In fact, we demonstrated that MPTP administration into the SNpc, and consequent loss of its dopaminergic neurons, leads to a delay in REM sleep phase entrance (57). Structurally, there is an interaction among areas which are rich in dopaminergic neurons, such as substantia nigra pars compacta, and brain nuclei controlling the sleep/ wake cycle, such as the hypothalamus, 
pedunculopontine nucleus, locus coeruleus and dorsal raphe nuclei (46). Also, REMSD induces up-regulation of D2 dopaminergic receptors in the rat brain (58). In fact, striatal dopamine levels were reduced in animals challenged with rotenone alone. Nevertheless, as already mentioned, animals which received rotenone, followed by REMSD, did not present decreased dopamine level within the striatum, which might help explain the absence of a memory impairment $(34,59)$. Similarly, animals which received raclopride (a D2 dopamine receptor antagonist), following rotenone administration, did not present the recognition memory impairment observed in the animals exposed to rotenone alone (31). In fact, the involvement of the dopaminergic system in memory consolidation is extensively described. Individuals that received L-Dopa (a dopamine precursor) showed an increase in long-term memory consolidation $(60,61)$. Here, we observed a significant increase in striatal Mmp-9 mRNA and protein expression levels, as well as in Mmp-9/ Reck and Mmp-7/ Reck expression ratios in the Sham/REMSD animals. These data support the hypothesis of a higher ECM remodeling in the brain, in which Mmps play a crucial role in the brain following sleep deprivation (62-65).

Moreover, the positive correlation of $M m p /$ Reck expression ratios between the SNpc and the striatum, observed upon rotenone infusion, is reversed by REMSD. These data suggest that the desynchronization of the ECM turnover status in these two structures is associated with an improved cognitive phenotype. Taken together, our results suggest a potential association between an increased Mmp7/Reck and -9/Reck expression ratios, positively correlating with dopamine receptors expression in the SNpc and a positive effect on cognitive performance in REMSD animals with Parkinson's disease.

\section{References}

1. Tysnes OB, Storstein A. Epidemiology of Parkinson's disease. J Neural Transm. 2017;124(8):901-5.

2. GBD 2015 Neurobiological Disorders Collaborator Group. Global, regional, and national burden of neurological disorders during 1990-2015: a systematic analysis for the Global Burden of Disease Study 2015. The Lancet Neurobiology. 2017; 16(11): 877-897.

3. Dorsey ER, Sherer T, Okun MS, Bloem BR. The Emerging Evidence of the Parkinson Pandemic. J Parkinsons Dis. 2018; 8:3-8.

4. Van Den Eeden SK, Tanner CM, Bernstein AL, Fross RD, Leimpeter A, Bloch DA, et al. Incidence of Parkinson's disease: variation by age, gender, and race/ethnicity. Am J Epidemiol. 2003;157(11):1015-22.

5. Parkinson J. An essay on the shaking palsy. J Neuropsychiatry Clin Neurosci. 2002;14(2):223-36; discussion 222.

6. Claassen D. Sleep disturbances in Parkinson's disease patients and management options. Nat Sci Sleep. 2011; 3:125-33.

7. Lima MMS, Martins EF, Delattre AM, Proenca MB, Mori MA, Carabelli B, et al. Motor and non-motor features of Parkinson's disease - a review of clinical and experimental studies. CNS Neurol Disord Drug Targets. 2012;11(4):439-49. 
8. Mercier F. Fractones: extracellular matrix niche controlling stem cell fate and growth factor activity in the brain in health and disease. Cell Mol Life Sci. 2016;73(24):4661-4674.

9. Dauth S, Grevesse T, Pantazopoulos H, Campbell PH, Maoz BM, Berretta S, Parker KK1.Extracellular matrix protein expression is brain region dependent. J Comp Neurol. 2016;524(7):1309-36.

10. Dzwonek J, Rylski M, Kaczmarek L. Matrix metalloproteinases and their endogenous inhibitors in neuronal physiology of the adult brain. In: FEBS Letters. 2004;567(1):129-35.

11. Yong VW, Power C, Forsyth P, Edwards DR. Metalloproteinases in biology and pathology of the nervous system. Nat Rev Neurosci. 2001;2(7):502-11.

12. Itoh $\mathrm{Y}$, Nagase H. Matrix metalloproteinases in cancer. Essays Biochem. 2002;38:21-36.

13. Lorenzl S, Albers DS, Narr S, Chirichigno J, Beal MF. Expression of MMP-2, MMP-9, and MMP-1 and their endogenous counterregulators TIMP-1 and TIMP2 in postmortem brain tissue of Parkinson's disease. Exp Neurol. 2002;178(1):13-20.

14. Rosenberg GA. Matrix metalloproteinases and their multiple roles in neurodegenerative diseases. Lancet Neurol. 2009;8(2):205-16.

15. Nagy V. Matrix Metalloproteinase-9 Is Required for Hippocampal Late-Phase Long-Term Potentiation and Memory. J Neurosci. 2006; 26(7):1923-34.

16. Shapiro ML, Eichenbaum H. Hippocampus as a memory map: Synaptic plasticity and memory encoding by hippocampal neurons. Hippocampus. 1999;9(4):36584.

17. Brown TE, Wilson AR, Cocking DL, Sorg BA. Inhibition of matrix metalloproteinase activity disrupts reconsolidation but not consolidation of a fear memory. Neurobiol Learn Mem. 2009 ;91(1):66-72.

18. Meighan SE, Meighan PC, Choudhury P, Davis CJ, Olson ML, Zornes PA, et al. Effects of extracellular matrix-degrading proteases matrix metalloproteinases 3 and 9 on spatial learning and synaptic plasticity. J Neurochem. 2006;96(5):1227-41.

19. Mizoguchi H, Ibi D, Takuma K, Toth E, Sato J, Itohara S, et al. Alterations of Emotional and Cognitive Behaviors in Matrix Metallo- proteinase-2 and -9Deficient Mice. Behav Sci. 2010;19-25.

20. Wright JW, Brown TE, Harding JW. Inhibition of hippocampal matrix metalloproteinase-3 and -9 disrupts spatial memory. Neural Plast. 2007; 2007:73813(1-8).

21. He X, Zhang L, Yao X, Hu J, Yu L, Jia H, et al. Association Studies of MMP-9 in Parkinson's Disease and Amyotrophic Lateral Sclerosis. PLoS One. 2013;8(9):1-5.

22. Chen L, Tian S, Ke J. Rapid eye movement sleep deprivation disrupts 
consolidation but not reconsolidation of novel object recognition memory in rats.Neurosci Lett. 2014; 563:12-6.

23. Li S, Tian $Y$, Ding $Y$, Jin $X$, Yan $C$, Shen $X$. The effects of rapid eye movement sleep deprivation and recovery on spatial reference memory of young rats. Learn Behav. 2009; 37(3):246-53.

24. Sherer TB, Betarbet R, Testa CM, Seo BB, Richardson JR, Kim JH, et al. Mechanism of toxicity in rotenone models of Parkinson's disease. J Neurosci. 2003;23(34):10756-64.

25. Paxinos G, Watson C. The Rat Brain in Stereotaxic Coordinates Sixth Edition by. Acad Press. 2006;170:547612.

26. Cohen HB, Dement WC. Sleep: changes in threshold to electroconvulsive shock in rats after deprivation of "paradoxical" phase. Science (80- ). 1965;150(3701):1318-9.

27. Santos P Dos, Targa ADS, Noseda ACD, Rodrigues LS, Fagotti J, Lima MMS. Cholinergic Oculomotor Nucleus Activity Is Induced by REM Sleep Deprivation Negatively Impacting on Cognition. Mol Neurobiol. 2017;54(7):5721-5729.

28. Machado RB, Hipólide DC, Benedito-Silva AA, Tufik S. Sleep deprivation induced by the modified multiple platform technique: Quantification of sleep loss and recovery. Brain Res. 2004;1004(1-2):45-51.

29. Pfaffl MW. A new mathematical model for relative quantification in. $2001 ; 29(9): 16-21$.

30. Vandesompele, J., De Preter, K., Pattyn, F., Poppe, B., Van Roy, N., De Paepe, A., Speleman F. Accurate normalization of real-time quantitative RT-PCR data by geometric averaging of multiple internal control genes. Genome Biol. 2002; 3(7): research0034.1-research0034.11.

31. Targa ADS, Noseda ACD, Rodrigues LS, Aurich MF, Lima MMS. REM sleep deprivation and dopaminergic D2 receptors modulation increase recognition memory in an animal model of Parkinson's disease. Behav Brain Res. 2018;339:239-48.

32. Soto-Rodriguez S, Lopez-Armas G, Luquin S, Ramos-Zuñiga R, JaureguiHuerta F, Gonzalez-Perez O, Gonzalez-Castañeda RE.Rapid Eye Movement Sleep Deprivation Produces Long-Term Detrimental Effects in Spatial Memory and Modifies the Cellular Composition of the Subgranular Zone.Front Cell Neurosci. 2016;10:132.

33. Nagy V, Bozdagi $\mathrm{O}$, Huntley GW. The extracellular protease matrix metalloproteinase- 9 is activated by inhibitory avoidance learning and required for long-term memory. Learn Mem. 2007;14(10):655-64.

34. Dos Santos ACD, Castro MA V, Jose EAK, Delattre AM, Dombrowski PA, Da Cunha $C$, et al. REM sleep deprivation generates cognitive and neurochemical disruptions in the intranigral rotenone model of Parkinson's disease. J Neurosci Res. 2013;91(11):1508-16.

35. Noseda ACD, Targa ADS, Rodrigues LS, Aurich MF, Lima MMS. REM sleep deprivation promotes a dopaminergic influence in the striatal MT2 anxiolytic-like 
effects. Sleep Sci . 2016;9(1):47-54.

36. Niijima F, Aito HS, Urai SM, Rai YA, Akagawasai ON, No KTAN, et al. Effects of atomoxetine on levels of monoamines and related substances in discrete brain regions in mice intermittently deprived of rapid eye movement sleep. Biol $\{\&\}$ Pharm Bull. 2010;33(4):617-21.

37. Geinisman Y, Berry RW, Disterhoft JF, Power JM, der Zee EA Van. Associative learning elicits the formation of multiple-synapse boutons. J Neurosci. 2001;21(15):5568-73.

38. Bailey $\mathrm{CH}$, Kandel ER, Harris KM. Structural components of synaptic plasticity and memory consolidation. Cold Spring Harb Perspect Biol. 2015; 7(7):a021758.

39. Lazarov $O$, Hollands $C$. Hippocampal neurogenesis: learning to remember. 2016;8(5):583-92.

40. Weintraub D, Doshi J, Koka D, Davatzikos C, Siderowf AD, Duda JE, et al. Neurodegeneration across stages of cognitive decline in Parkinson's disease. Arch Neurol. 2011;68(12):1562-8.

41. Wright JW, Kramár EA, Meighan SE, Harding JW. Extracellular matrix molecules, long-term potentiation, memory consolidation and the brain angiotensin system. Peptides. 2002;23(1):221-46.

42. Kim E-M, Hwang O. Role of matrix metalloproteinase-3 in neurodegeneration. $\mathrm{J}$ Neurochem. 2011;116(1):22-32.

43. Mizoguchi H, Nakade J, Tachibana M, Ibi D, Someya E, Koike H, et al. Matrix Metalloproteinase-9 Contributes to Kindled Seizure Development in Pentylenetetrazole-Treated Mice by Converting Pro-BDNF to Mature BDNF in the Hippocampus. J Neurosci. 2011; 7;31(36):12963-71.

44. Groch S, Wilhelm I, Diekelmann S, Born J. The role of REM sleep in the processing of emotional memories: Evidence from behavior and event-related potentials. Neurobiol Learn Mem. 2013;99:1-9.

45. Tononi G, Cirelli C. Sleep function and synaptic homeostasis. Sleep Med Rev. 2006;10(1):49-62.

46. Monti JM, Monti D. The involvement of dopamine in the modulation of sleep and waking. Sleep Med Rev. 2007;11(2):113-33.

47. Tsunematsu T, Tabuchi S, Tanaka KF, Boyden ES, Tominaga M, Yamanaka A. Long-lasting silencing of orexin/hypocretin neurons using archaerhodopsin induces slow-wave sleep in mice. Behav Brain Res. 2013;255:64-74.

48. Schwartz MD, Kilduff TS. THE NEUROBIOLOGY OF SLEEP AND WAKEFULNESS. 2016;8(5):583-92.

49. Levi-Montalcini R. The nerve growth factor 35 years later. Science. 1987; 237(4819):1154-62.

50. Indo Y. NGF-dependent neurons and neurobiology of emotions and feelings: Lessons from congenital insensitivity to pain with anhidrosis. Neuroscience and Biobehavioral Reviews. 2018; 39(3):375-91. 
51. Lorigados Pedre L, Pavón Fuentes N, Alvarez González L, McRae A, Serrano Sánchez T, Blanco Lescano L, et al. Nerve growth factor levels in parkinson disease and experimental parkinsonian rats. Brain Res. 2002; 952(1):122-7.

52. Salinas M, Diaz R, Abraham NG, De Galarreta CMR, Cuadrado A. Nerve growth factor protects against 6-hydroxydopamine-induced oxidative stress by increasing expression of heme oxygenase-1 in a phosphatidylinositol 3-kinasedependent manner. J Biol Chem. 2003; 278(16):13898-904.

53. Pascual A, Hidalgo-Figueroa M, Gómez-Díaz R, López-Barneo J. GDNF and protection of adult central catecholaminergic neurons. Journal of Molecular Endocrinology. 2011; 46(3): R83-92.

54. Ibáñez CF, Andressoo JO. Biology of GDNF and its receptors - Relevance for disorders of the central nervous system. Neurobiology of Disease. 2017; 97(Pt B) :80-89.

55. Annese V, Herrero MT, Di Pentima M, Gomez A, Lombardi L, Ros CM, et al. Metalloproteinase- 9 contributes to inflammatory glia activation and nigro-striatal pathway degeneration in both mouse and monkey models of 1-methyl-4-phenyl1,2,3,6-tetrahydropyridine (MPTP)-induced Parkinsonism. Brain Struct Funct. 2015;220(2):703-27.

56. Lorenzl S, Calingasan N, Yang L, Albers DS, Shugama S, Gregorio J, et al. Matrix metalloproteinase-9 is elevated in 1-methyl-4-phenyl-1,2,3,6tetrahydropyridine-induced parkinsonism in mice. Neuromolecular Med. 2004;5(2):119-32.

57. Lima MMS, Andersen ML, Reksidler AB, Vital MABF, Tufik S. The role of the substantia nigra pars compacta in regulating sleep patterns in rats. PLoS One. 2007;2(6):1-7.

58. Nunes GP, Tufik S, Nobrega JN. Autoradiographic analysis of D1 and D2 dopaminergic receptors in rat brain after paradoxical sleep deprivation. Brain Res Bull. 1994; 34(5):453-6.

59. Niijima F, Aito HS, Urai SM, Rai YA, Akagawasai ON, No KTAN, et al. Effects of atomoxetine on levels of monoamines and related substances in discrete brain regions in mice intermittently deprived of rapid eye movement sleep. Biol $\{\&\}$ Pharm Bull. 2010;33(4):617-21.

60. Baudonnat M, Huber A, David V, Walton ME. Heads for learning, tails for memory: Reward, reinforcement and a role of dopamine in determining behavioral relevance across multiple timescales. Front Neurosci. 2013;7:1-14.

61. Eckart C, Fuentemilla L, Bauch EM, Bunzeck N. Dopaminergic stimulation facilitates working memory and differentially affects prefrontal low theta oscillations. Neuroimage . 2014;94:185-92.

62. Szklarczyk A, Lapinska J, Rylski M, Mckay RDG, Kaczmarek L. Matrix Metalloproteinase-9 Undergoes Expression and Activation during Dendritic Remodeling in Adult Hippocampus. Neuroscience. 2002; 22(3):920-30.

63. He B, Peng H, Zhao Y, Zhou H, Zhao Z. Modafinil treatment prevents REM sleep deprivation-induced brain function impairment by increasing MMP-9 
expression. Brain Res. 2011; 1426:38-42.

64. Cooper JM, Halter KA, Prosser RA. Circadian rhythm and sleep-wake systems share the dynamic extracellular synaptic milieu. Neurobiology of Sleep and Circadian Rhythms. 2018; 5:15-36.

65. Wright JW, Reichert JR, Davis CJ, Harding JW. Neural plasticity and the brain renin-angiotensin system. Neuroscience and Biobehavioral Reviews. 2002; 26(5):529-52.

\section{Supplementary Table 1. Sequence and concentration of the primers used in the qRT-PCR assays.}

\begin{tabular}{|c|c|c|}
\hline \multirow[b]{2}{*}{ Target } & \multicolumn{2}{|c|}{ Primers List } \\
\hline & Sequence & $\begin{array}{l}\text { Final Concentration in the reaction } \\
\qquad(\mathrm{nM})\end{array}$ \\
\hline B-actina & $\begin{array}{l}\text { F>CGAGTACAACCTTCTTGCAGC } \\
\text { R>ATACCCACCATCACACCCTGG }\end{array}$ & 600 \\
\hline HPRT & $\begin{array}{l}\text { F>CCCAGCGTCGTGATTAGTGA } \\
\text { R>TGGCCTCCCATCTCCTTCAT }\end{array}$ & 600 \\
\hline Reck & $\begin{array}{l}\text { F>CCCAGATTATTGCCCAGAGACA } \\
\text { R>ACACCTGGCAAAGATGAGTTCA }\end{array}$ & 800 \\
\hline Mmp-3 & $\begin{array}{l}\mathrm{F}>\text { TTCCTCTGAAACTTGGCGCA } \\
\mathrm{R}>\mathrm{ACTTGAGGTTGACTGGTGCC}\end{array}$ & 800 \\
\hline Mmp-7 & $\begin{array}{l}\text { F>TGATGGGCCAGGAAACACTC } \\
\text { R>GTTCACTCCTGAGTCCTCACC }\end{array}$ & 600 \\
\hline Mmp-9 & $\begin{array}{l}\text { F>GCATCTGTATGGTCGTGGCT } \\
\text { R>TGCAGTGGGACACATAGTGG }\end{array}$ & 800 \\
\hline Timp-2 & $\begin{array}{l}\text { F>ATGGCAACCCCATCAAGAGG } \\
\text { R>CCGCCTTCCCTGCAATTAGA }\end{array}$ & 800 \\
\hline GDNF & $\begin{array}{c}\text { F>CAGAGGGAAAGGTCGCAGAG } \\
\text { R>ATCAGTTCCTCCTTGGTTTCGTAG }\end{array}$ & 800 \\
\hline NGF & $\begin{array}{l}\text { F>AGCGCATCGCTCTCCTTCAC } \\
\text { R>TTGGCAAAGCCTTTATTGGGC }\end{array}$ & 800 \\
\hline
\end{tabular}



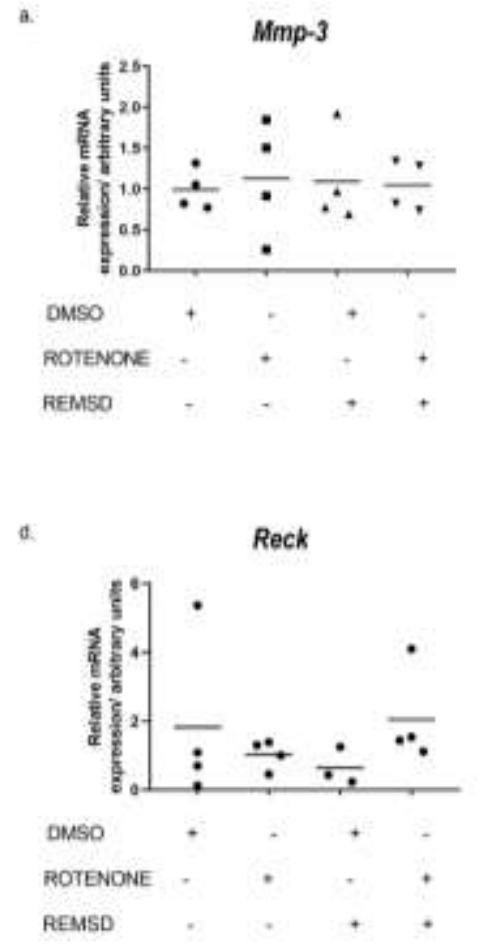

a.
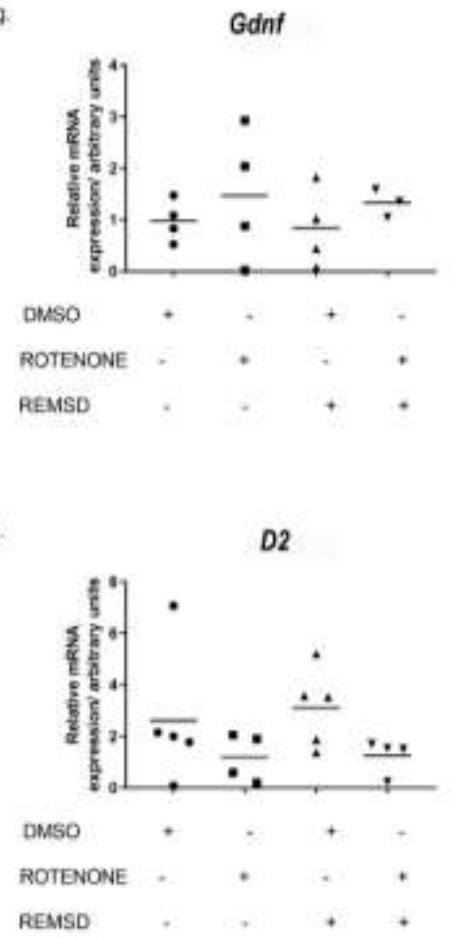

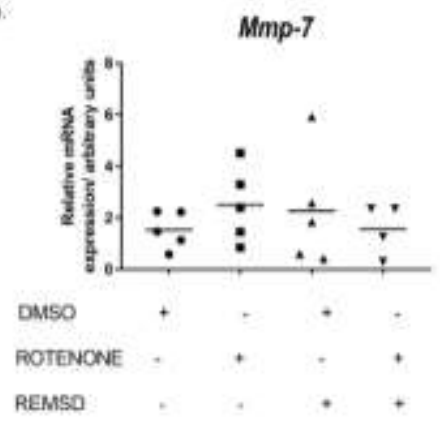

Mmp-3/Reck

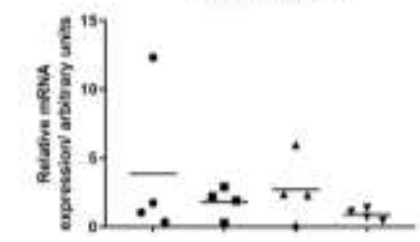

Daso

ROTENCNE

REMSO

n.

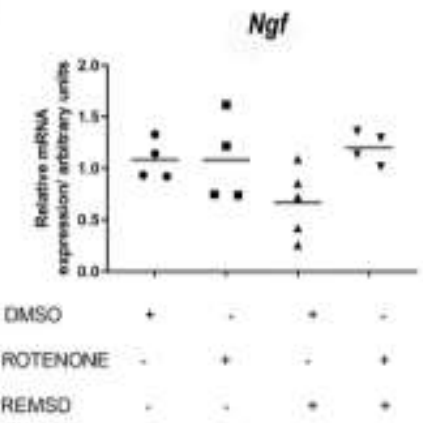

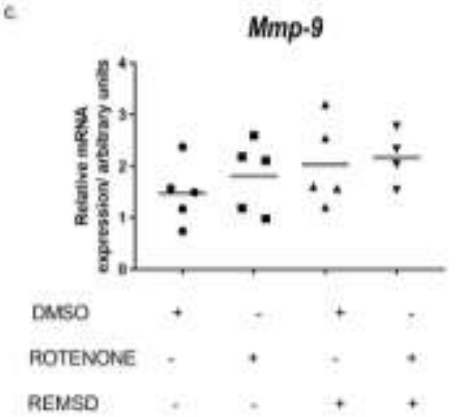

Timp-3

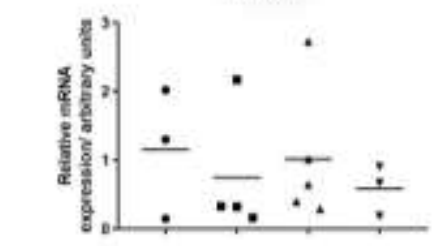

DMso

ROTENCWE.

REMSD

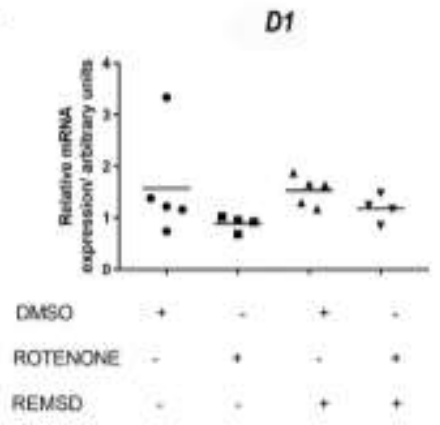

Supplementary figure 1 Expression profile in the hippocampus upon rotenone infusion and/or REM sleep deprivation. mRNA expression profiles of a. Mmp-3, b. Mmp-7, c. Mmp-9, d. Reck, e. Mmp-3/ Reck ratio, f. Timp-3, g. GDNF, h. NGF, i. D1, and j. D2 determined by qRTPCR ( $\mathrm{n}=3$ to 5 for each group). 

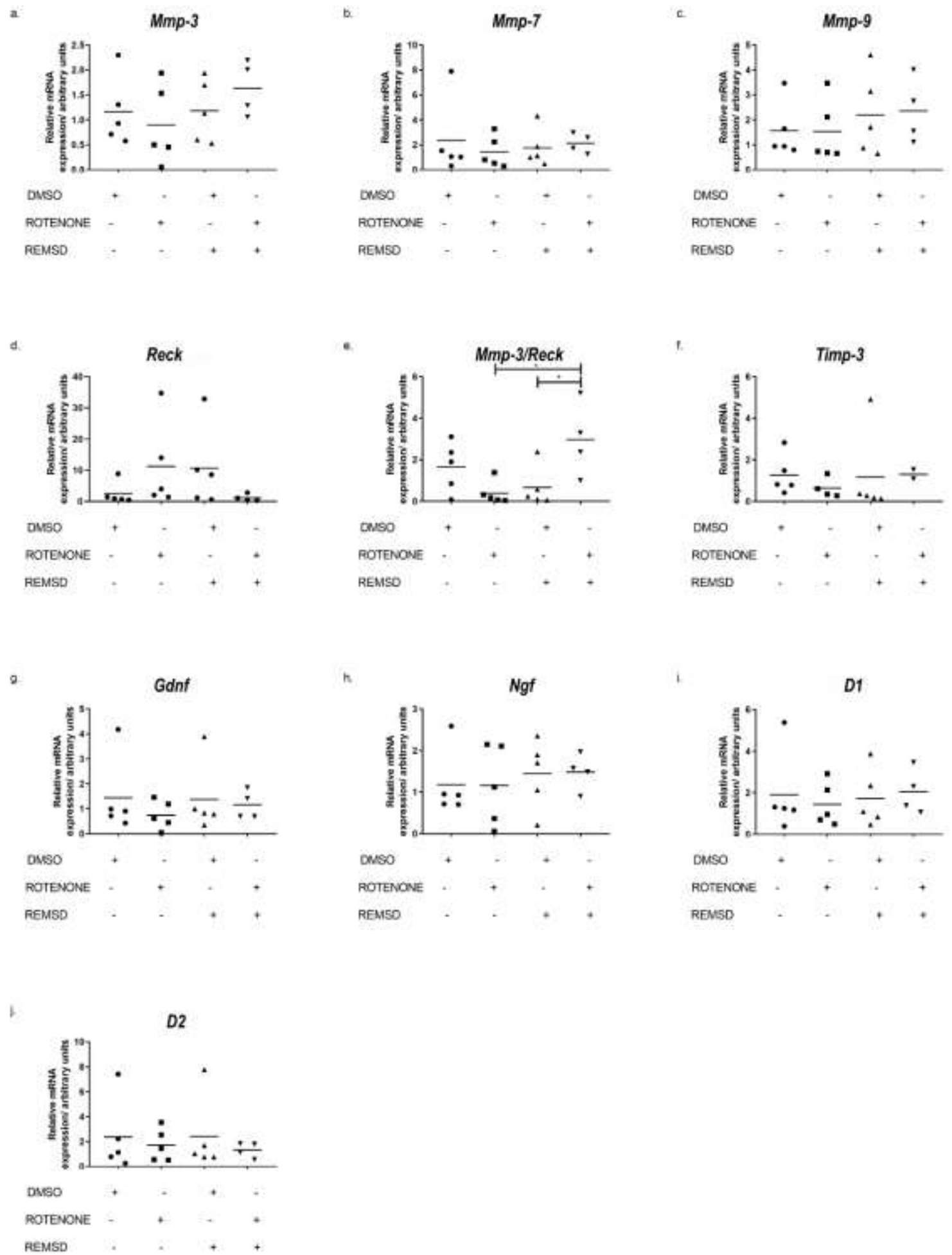

Supplementary figure 2 Expression profile in the hypothalamus upon rotenone infusion and/or REM sleep deprivation. mRNA mRNA expression profiles of a. Mmp-3, b. Mmp-7, c. $M m p-9$, d. Reck, e. Mmp-3/ Reck ratio, f. Timp-3, g. GDNF, h. NGF, i. D1, and j. D2 determined by qRT-PCR ( $n=3$ to 5 for each group). ${ }^{*}$ stands for $p \leq 0.05$. 

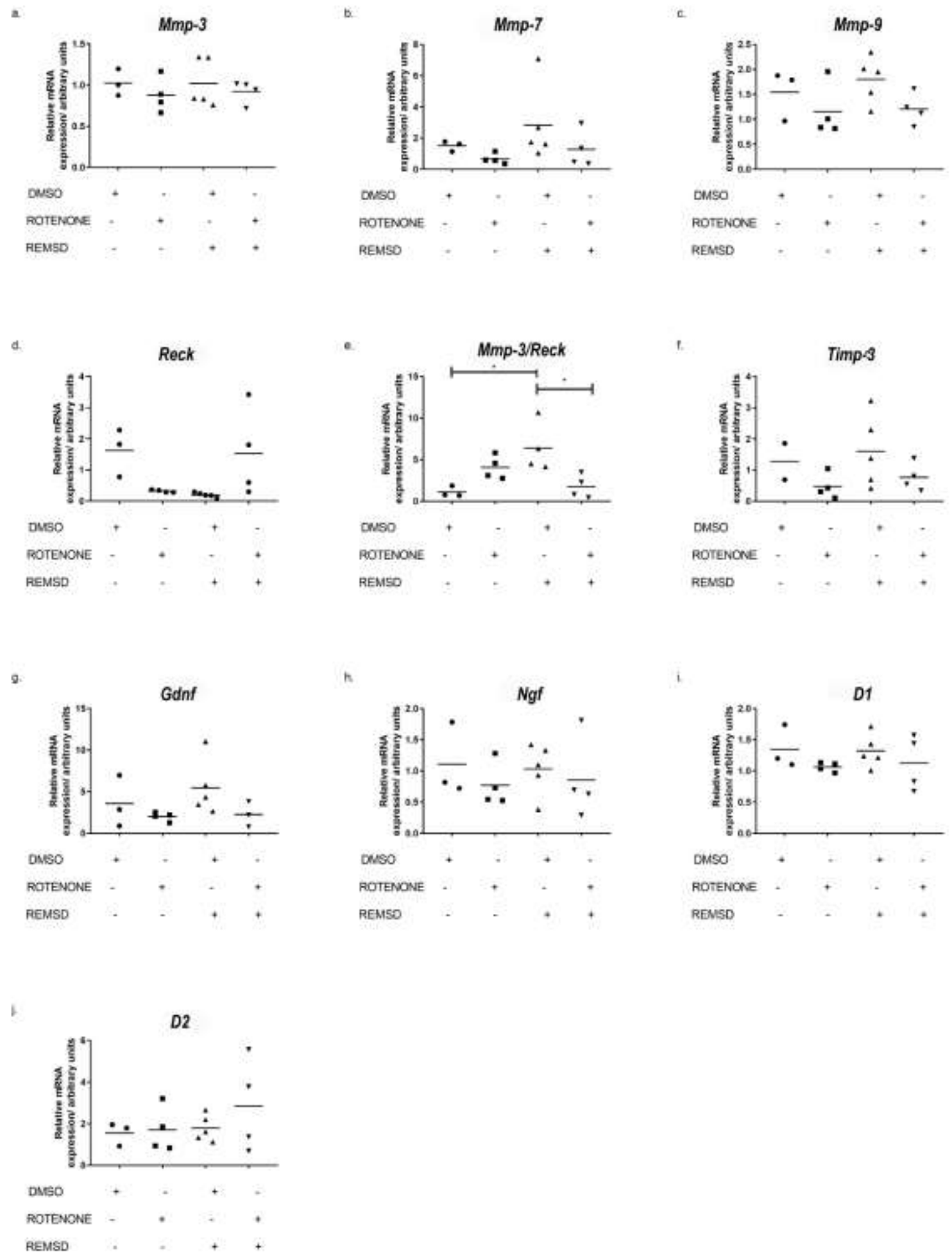

Supplementary figure 3 Expression profile in the striatum upon rotenone infusion and/or REM sleep deprivation. mRNA expression profiles of a. Mmp-3, b. Mmp-7, c. Mmp-9, d. Reck, e. Mmp-3/ Reck ratio, f. Timp-3, g. GDNF, h. NGF, i. D1, and j. D2 determined by qRT-PCR ( $\mathrm{n}=$ 3 to 5 for each group). ${ }^{*}$ stands for $p \leq 0.05$. 

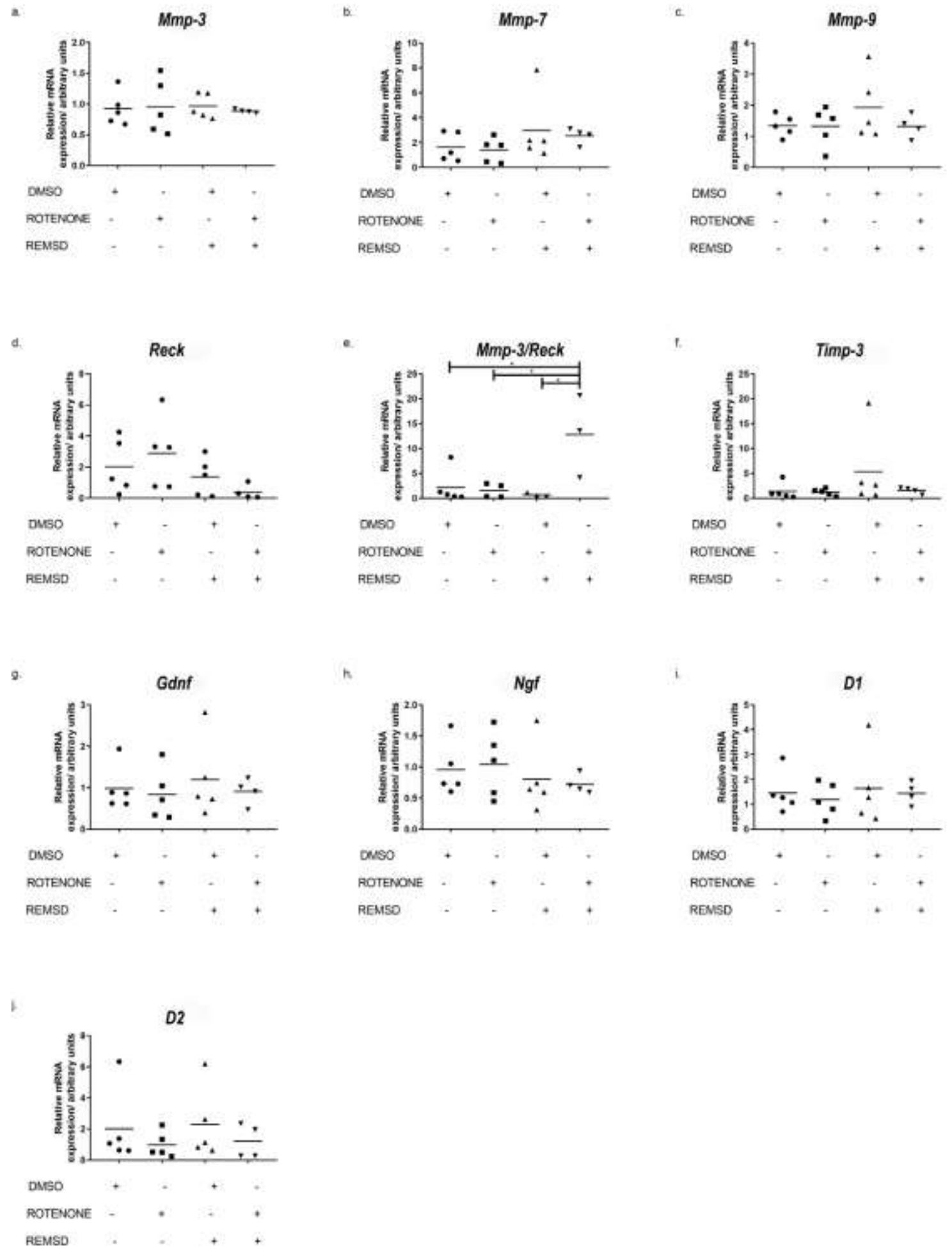

Supplementary figure 4 Expression profile in the substantia nigra upon rotenone infusion and/or REM sleep deprivation. mRNA expression profiles of a. Mmp-3, b. Mmp-7, c. Mmp-9, d. Reck, e. Mmp-3/ Reck ratio, f. Timp-3, g. GDNF, h. NGF, i. D1, and j. D2 determined by qRTPCR ( $n=3$ to 5 for each group). ${ }^{*}$ stands for $p \leq 0.05$. 


\section{Conclusões}

No presente trabalho, observamos um aumento significativo nos níveis de expressão de mRNA e proteína de Mmp-9 no estriado, bem como na razão de expressão de Mmp-9/Reck e Mmp-7/Reck nos animais Sham/REMSD. Esses dados corroboram a hipótese de um remodelamento mais alto da MEC no cérebro, no qual as Mmps desempenham um papel crucial, após a privação do sono. Além disso, a correlação positiva das razões de expressão Mmp/Reck entre a SNpc e o estriado observado após a infusão de rotenona é revertida pelo REMSD. Esses dados sugerem que a dessincronização do estado de renovação da MEC nessas duas estruturas está associada a um fenótipo cognitivo melhorado. Em conjunto, nossos resultados sugerem uma potencial associação entre uma razão de expressão aumentada de Mmp-7/Reck e -9/Reck, positivamente correlacionada com a expressão de receptores de dopamina no $\mathrm{SNpc}$ e um efeito positivo no desempenho cognitivo em animais privados de sono REM com doença de Parkinson. 


\section{Referências}

1. Parkinson J. An essay on the shaking palsy. J Neuropsychiatry Clin Neurosci. 2002;14(2):223-36; discussion 222

2. Segura-Aguilar J, Paris I, Muñoz P, Ferrari E, Zecca L, Zucca FA. Protective and toxic roles of dopamine in Parkinson's disease. J Neurochem. 2014;129(6):898915.

3. Paris I, Lozano J, Perez-Pastene C, Muñoz P, Segura-Aguilar J. Molecular and neurochemical mechanisms in PD pathogenesis. Neurotox Res. 2009;16(3):2719.

4. Hauser D, Hastings T. Mitochondrial dysfunction and oxidative stress in Parkinson's disease and monogenic parkinsonism. Neurobiol Dis. 2013;35-42.

5. Muñoz P, Cardenas S, Huenchuguala S, Briceño A, Couve E, Paris I, et al. DTdiaphorase prevents aminochrome-induced alpha-synuclein oligomer formation and neurotoxicity. Toxicol Sci. 2015;145(1):37-47.

6. Arriagada C, Paris I, Sanchez De Las Matas MJ, Martinez-Alvarado P, Cardenas $\mathrm{S}$, Castañeda $\mathrm{P}$, et al. On the neurotoxicity mechanism of leukoaminochrome osemiquinone radical derived from dopamine oxidation: Mitochondria damage, necrosis, and hydroxyl radical formation. Neurobiol Dis. 2004;16(2):468-77.

7. Susin SA, Zamzami N, Castedo M, Hirsch T, Marchetti P, Macho A, et al. Bcl-2 inhibits the mitochondrial release of an apoptogenic protease. J Exp Med. 1996;184(4):1331-41.

8. Jagmag SA, Tripathi N, Shukla SD, Maiti S. Evaluation of Models of Parkinson ' s Disease. 2016;9(January).

9. Ungerstedt U. 6-HYDROXY-DOPAMINE INDUCED DEGENERATION OF CENTRAL MONOAMINE NEURONS. 1968;5:107-10.

10. Blandini F, Armentero M-T. Animal models of Parkinson's disease. FEBS J [Internet]. 2012;279(7):1156-66. Available from:

http://doi.wiley.com/10.1111/j.1742-4658.2012.08491.x

11. Kirik D, Rosenblad C, Björklund A. Characterization of behavioral and neurodegenerative changes following partial lesions of the nigrostriatal dopamine system induced by intrastriatal 6-hydroxydopamine in the rat. Exp Neurol. 1998;152(2):259-77.

12. Sauer H, Oertel WH. Progressive degeneration of nigrostriatal dopamine neurons following intrastriatal terminal lesions with 6-hydroxydopamine: A combined retrograde tracing and immunocytochemical study in the rat. Neuroscience. 1994;59(2):401-15.

13. Dauer W, Przedborski S. Parkinson's disease: Mechanisms and models. Neuron. 
2003;39(6):889-909.

14. Ovadia A, Zhang Z, Gash DM. Increased susceptibility to MPTP toxicity in middle-aged rhesus monkeys. Neurobiol Aging. 1995;16(6):931-7.

15. Varastet M, Riche D, Maziere M, Hantraye P. Chronic MPTP treatment reproduces in baboons the differential vulnerability of mesencephalic dopaminergic neurons observed in parkinson's disease. Neuroscience. 1994;63(1):47-56.

16. McCormack AL, Thiruchelvam M, Manning-Bog AB, Thiffault C, Langston JW, Cory-Slechta DA, et al. Environmental risk factors and Parkinson's disease: Selective degeneration of nigral dopaminergic neurons caused by the herbicide paraquat. Neurobiol Dis. 2002;10(2):119-27.

17. Cicchetti F, Lapointe N, Roberge-Tremblay A, Saint-Pierre M, Jimenez L, Ficke BW, et al. Systemic exposure to paraquat and maneb models early Parkinson's disease in young adult rats. Neurobiol Dis. 2005;20(2):360-71.

18. Miller GW. Paraquat: The red herring of Parkinson's disease research. Toxicol Sci. 2007;100(1):1-2.

19. Srivastava P, Panda D. Rotenone inhibits mammalian cell proliferation by inhibiting microtubule assembly through tubulin binding. FEBS J.

2007;274(18):4788-801.

20. Sherer TB, Betarbet R, Testa CM, Seo BB, Richardson JR, Kim JH, et al. Mechanism of toxicity in rotenone models of Parkinson's disease. J Neurosci [Internet]. 2003;23(34):10756-64. Available from:

http://www.ncbi.nlm.nih.gov/entrez/query.fcgi?cmd=Retrieve \&db=PubMed\&do $\mathrm{pt}=$ Citation\&list_uids $=14645467$

21. Talpade DJ, Greene JG, Higgins DS, Greenamyre JT. In vivo labeling of mitochondrial complex I (NADH:Ubiquinone oxidoreductase) in rat brain using [3H]dihydrorotenone. J Neurochem. 2000;75(6):2611-21.

22. Rasch B, Born J. About sleep's role in memory. Vol. 93, Physiological reviews. 2013. p. 681-766.

23. Borbely AA, Achermann P. Sleep homeostasis and models of sleep regulation [see comments]. J Biol Rhythm. 1999;14(6):557-68.

24. Van Cauter E, Spiegel K, Tasali E, Leproult R. Metabolic consequences of sleep and sleep loss. Sleep Med. 2008;9(SUPPL. 1):1-11.

25. Eugene AR, Masiak J. The Neuroprotective Aspects of Sleep. 2015;33(4):395401 .

26. Aton SJ, Seibt J, Dumoulin M, Jha SK, Steinmetz N, Coleman T, et al. Mechanisms of sleep-dependent consolidation of cortical plasticity. Sleep 
(Rochester). 2009;61(3):454-66.

27. Seibt J, Dumoulin MC, Aton SJ, Coleman T, Watson A, Naidoo N, et al. Protein synthesis during sleep consolidates cortical plasticity in vivo. 2012;22(8):676-82.

28. Marks GA, Shaffery JP, Oksenberg A, Speciale SG, Roffwarg HP. A functional role for REM sleep in brain maturation. Behav Brain Res. 1995;69(1-2):1-11.

29. Matsuzaki M, Honkura N, Ellis-Davies GCR, Kasai H. Structural basis of longterm potentiation in single dendritic spines. Nature. 2004;429(6993):761-6.

30. Yang G, Sau C, Lai W, Cichon J, Li W. Sleep promotes branch-specific formation of dendritic spines after learning. 2014;344(6188):1173-8.

31. Bryant PA, Trinder J, Curtis N. Sick and tired: does sleep have a vital role in the immune system? Nat Rev Immunol. 2004;

32. Harrison Y, Horne J a. Sleep loss and temporal memory. Q J Exp Psychol A. 2000;

33. Krause AJ, Simon E Ben, Mander BA, Greer SM, Saletin JM, GoldsteinPiekarski AN, et al. The sleep-deprived human brain. Nature Reviews Neuroscience. 2017.

34. Meerlo P, Havekes R, Steiger A. Chronically restricted or disrupted sleep as a causal factor in the development of depression. Curr Top Behav Neurosci. 2015;

35. Abel T, Havekes R, Saletin JM, Walker MP. Sleep, plasticity and memory from molecules to whole-brain networks. Current Biology. 2013.

36. Havekes R, Meerlo P, Abel T. Animal studies on the role of sleep in memory: From behavioral performance to molecular mechanisms. Curr Top Behav Neurosci. 2015;

37. Walker MP. Cognitive consequences of sleep and sleep loss. Sleep Med. 2008;

38. Havekes R, Abel T. The tired hippocampus: the molecular impact of sleep deprivation on hippocampal function. Current Opinion in Neurobiology. 2017.

39. Kreutzmann JC, Havekes R, Abel T, Meerlo P. Sleep deprivation and hippocampal vulnerability: Changes in neuronal plasticity, neurogenesis and cognitive function. Neuroscience [Internet]. 2015;309:173-90. Available from: http://dx.doi.org/10.1016/j.neuroscience.2015.04.053

40. Saletin JM, Goldstein-Piekarski AN, Greer SM, Stark S, Stark CE, Walker MP. Human Hippocampal Structure: A Novel Biomarker Predicting Mnemonic Vulnerability to, and Recovery from, Sleep Deprivation. J Neurosci. 2016;

41. Short M a, Banks S. Sleep Deprivation and Disease. Sleep Deprivation Dis. 2014;13-26. 
42. Patti CL, Zanin K a, Sanday L, Kameda SR, Fernandes-Santos L, Fernandes H a, et al. Effects of sleep deprivation on memory in mice: role of state-dependent learning. Sleep. 2010;33(12):1669-79.

43. Smith C, Kitahama K, Valatx JL, Jouvet M. Increased paradoxical sleep in mice during acquisition of a shock avoidance task. Brain Res. 1974;

44. Smith C, Young J, Young W. Prolonged increases in paradoxical sleep during and after avoidance-task acquisition. Sleep. 1980;

45. Smith C, Wong PTP. Paradoxical Sleep Increases Predict Successful Learning in a Complex Operant Task. Behav Neurosci. 1991;

46. Fishbein W, Gutwein BM. Paradoxical sleep and memory storage processes. Behav Biol. 1977;

47. Smith C, Butler S. Paradoxical sleep at selective times following training is necessary for learning. Physiol Behav. 1982;

48. Smith C, MacNeill C. A paradoxical sleep-dependent window for memory 53-56 $\mathrm{h}$ after the end of avoidance training. Psychobiology. 1993;

49. Mirmiran M, Van Den Dungen H, Uylings HBM. SLEEP PATTERNS DURING REARING UNDER DIFFERENT ENVIRON- MENTAL CONDITIONS IN JUVENILE RATS M. Brain. 1982;234(March 1981):111-21.

50. Rahman A, Languille S, Lamberty Y, Babiloni C, Perret M, Bordet R, et al. Sleep Deprivation Impairs Spatial Retrieval but Not Spatial Learning in the NonHuman Primate Grey Mouse Lemur. PLoS One. 2013;8(5):1-8.

51. Ward CP, Wooden JI, Kieltyka R. Effects of Sleep Deprivation on Spatial Learning and Memory in Juvenile and Young Adult Rats. 2017;4(11):109-16.

52. Walker MP. Issues surrounding sleep-dependent memory consolidation and plasticity. Cell Mol Life Sci. 2004;61(24):3009-15.

53. Graves L, Heller E, Pack A, Abel T. Sleep deprivation selectively impairs memory consolidation for contextual fear conditioning. Learn Mem [Internet]. 2003;10(3):168-176. Available from: http://learnmem.cshlp.org/content/10/3/168.short

54. Lima MMS, Martins EF, Delattre AM, Proenca MB, Mori MA, Carabelli B, et al. Motor and non-motor features of Parkinson's disease - a review of clinical and experimental studies. CNS Neurol Disord Drug Targets. 2012;11(4):439-49.

55. Ferini-Strambi L, Fantini ML, Zucconi M, Castronovo V, Marelli S, Oldani A, et al. REM sleep behaviour disorder. Arch Psychiatry Psychother. 2005;7(4):27-31. 
56. Fahn S. Description of Parkinson' s Disease as a Clinical Syndrome. Ann New York Acad Sci. 2003;991:1-14.

57. Roychowdhury S, Forsyth DR. Sleep disturbance in Parkinson disease. J Clin Gerontol Geriatr. 2012;3(2):53-61.

58. Comella CL. Sleep disorders in Parkinson's disease: An overview. Mov Disord. 2007;22(SUPPL. 17).

59. Alóe F, Azevedo AP De, Hasan R. Sleep-wake cycle mechanisms. Rev Bras Psiquiatr. 2005;27 Suppl 1(11):33-9.

60. Costa e Silva JA. Sleep disorders in psychiatry. Metabolism. 2006;55(SUPPL. 2):40-4.

61. Monti JM, Torterolo P, Pandi Perumal SR. The effects of second generation antipsychotic drugs on sleep variables in healthy subjects and patients with schizophrenia. Sleep Med Rev. 2016;(October):1-8.

62. Dos Santos ACD, Castro MA V, Jose EAK, Delattre AM, Dombrowski PA, Da Cunha $\mathrm{C}$, et al. REM sleep deprivation generates cognitive and neurochemical disruptions in the intranigral rotenone model of Parkinson's disease. J Neurosci Res. 2013;91(11):1508-16.

63. Korpos E, Wu C, Sorokin L. Multiple roles of the extracellular matrix in inflammation. Curr Pharm Des. 2009;15(12):1349-57.

64. Rozario T, Desimone DW. The Extracellular Matrix In Development and Morphogenesis: A Dynamic View. 2011;341(1):126-40.

65. Nicholson C, Kamali-Zare P, Tao L. Brain extracellular space as a diffusion barrier. Comput Vis Sci. 2011;

66. Dityatev A. Remodeling of extracellular matrix and epileptogenesis. In: Epilepsia. 2010.

67. Dityatev A, Schachner M. The extracellular matrix and synapses. Cell and Tissue Research. 2006.

68. Dityatev A, Schachner M. Extracellular matrix molecules and synaptic plasticity. Nat Rev Neurosci. 2003;

69. Bonneh-Barkay D, Wiley CA. Brain extracellular matrix in neurodegeneration. Brain Pathology. 2009.

70. Ruoslahti E. Brain extracellular matrix. Glycobiology. 1996;6(5):489-92.

71. Rauch U. Extracellular matrix components associated with remodeling processes 
in brain. Cell Mol Life Sci. 2004;

72. Ruoslahti E. Brain extracellular matrix. Glycobiology. 1996;6(5):489-92.

73. Bellail AC, Hunter SB, Brat DJ, Tan C, Van Meir EG. Microregional extracellular matrix heterogeneity in brain modulates glioma cell invasion. Int $\mathbf{J}$ Biochem Cell Biol. 2004;36(6):1046-69.

74. Zhang H, Baader SL, Sixt M, Kappler J, Rauch U. Neurocan-GFP Fusion Protein: A New Approach to Detect Hyaluronan on Tissue Sections and Living Cells. J Histochem Cytochem. 2004;52(7):915-22.

75. Itoh Y, Nagase H. Matrix metalloproteinases in cancer. Essays Biochem. 2002;38:21-36.

76. Yong VW, Power C, Forsyth P, Edwards DR. Metalloproteinases in biology and pathology of the nervous system. Nat Rev Neurosci. 2001;2(7):502-11.

77. Wang L, Zhang ZG, Zhang RL, Gregg SR, Hozeska-Solgot A, Letourneau Y, et al. Matrix Metalloproteinase 2 (MMP2) and MMP9 Secreted by ErythropoietinActivated Endothelial Cells Promote Neural Progenitor Cell Migration. J Neurosci. 2006;26(22):5996-6003.

78. Shapiro ML, Eichenbaum H. Hippocampus as a memory map: Synaptic plasticity and memory encoding by hippocampal neurons. Hippocampus. 1999;9(4):36584.

79. Nagy V, Bozdagi O, Matynia A, Balcerzyk M, Okulski P, Dzwonek J, et al. Matrix Metalloproteinase-9 Is Required for Hippocampal Late- Phase LongTerm Potentiation and Memory. 2006;150(2):137-43.

80. Overall CM, López-Otín C. Strategies for MMP inhibition in cancer: Innovations for the post-trial era. Nat Rev Cancer. 2002;2(9):657-72.

81. Fosang AJ, Neame PJ, Hardingham TE, Murphy G, Hamilton JA. Cleavage of cartilage proteoglycan between G1 and G2 domains by stromelysins. J Biol Chem. 1991;266(24):15579-82.

82. Murphy G, Cockett MI, Ward R V., Docherty AJP. Matrix metalloproteinase degradation of elastin, type IV collagen and proteoglycan. Biochem J [Internet]. 1991;277:277-9. Available from: http://www.pubmedcentral.nih.gov/articlerender.fcgi?artid=1151220\&tool=pmce ntrez\&rendertype $=$ abstract

83. Burke B. The role of matrix metalloproteinase 7 in innate immunity. Immunobiology. 2004;209(1-2):51-6.

84. Yadav L, Puri N, Rastogi V, Satpute P, Ahmad R, Kaur G. Matrix metalloproteinases and cancer - Roles in threat and therapy. Asian Pacific J Cancer Prev. 2014;15(3):1085-91. 
85. Oh J, Takahashi R, Kondo S, Mizoguchi A, Adachi E, Sasahara RM, et al. The membrane-anchored MMP inhibitor RECK is a key regulator of extracellular matrix integrity and angiogenesis. Cell. 2001;107(6):789-800.

86. Omura A, Matsuzaki T, Mio K, Ogura T, Yamamoto M, Fujita A, et al. RECK forms cowbell-shaped dimers and inhibits matrix metalloproteinase-catalyzed cleavage of fibronectin. J Biol Chem. 2009;284(6):3461-9.

87. Trombetta-Lima M, Maria S, Winnischofer B, Angelo M, Demasi A, Filho RA, et al. Isolation and characterization of novel $R E C K$ tumor suppressor gene splice variants. Oncotarget. 2015;6(32).

88. Kitange GJ, Mladek AC, Carlson BL, Schroeder MA, Jenny L, Cen L, et al. Inhibition of Histone Deacetylation Potentiates the Evolution of Acquired Temozolomide Resistance Linked to MGMT Upregulation in Glioblastoma Xenografts1. 2012;18(15):4070-9.

89. Lalezari S, Chou AP, Tran A, Solis OE, Khanlou N, Chen W, et al. Combined analysis of O6-methylguanine-DNA methyltransferase protein expression and promoter methylation provides optimized prognostication of glioblastoma outcome. Neuro Oncol. 2013;15(3):370-81.

90. Morioka Y, Monypenny J, Matsuzaki T, Shi S, Alexander DB, Kitayama H, et al. The membrane-anchored metalloproteinase regulator RECK stabilizes focal adhesions and anterior-posterior polarity in fibroblasts. Oncogene.

2009;28(11):1454-64.

91. Muraguchi T, Takegami Y, Ohtsuka T, Kitajima S, Chandana EPS, Omura A, et al. RECK modulates Notch signaling during cortical neurogenesis by regulating ADAM10 activity. Nat Neurosci. 2007;10(7):838-45.

92. Mcgaugh JL. Memory--a century of consolidation. Sci Res Libr pg. 2000;287(5451).

93. Nagy V, Bozdagi O, Huntley GW. The extracellular protease matrix metalloproteinase-9 is activated by inhibitory avoidance learning and required for long-term memory. Learn Mem. 2007;14(10):655-64.

94. Wright JW, Kramár EA, Meighan SE, Harding JW. Extracellular matrix molecules, long-term potentiation, memory consolidation and the brain angiotensin system. Peptides. 2002;23(1):221-46.

95. Nagy V, Bozdagi O, Matynia A, Balcerzyk M, Okulski P, Dzwonek J, et al. Matrix metalloproteinase-9 is required for hippocampal late-phase long-term potentiation and memory. J Neurosci. 2006;26(7):1923-34.

96. Smith C. Sleep states, memory processing, and dreams. Sleep Med Clin. 2012; 
97. Plihal W, Born J. Effects of early and late nocturnal sleep on priming and spatial memory. Psychophysiology. 1999;

98. Plihal W, Born J. Effects of early and late nocturnal sleep on declarative and procedural memory. J Cogn Neurosci. 1997;

99. Cavallero C. The quest for dream sources. In: Journal of Sleep Research. 1993.

100. Cicogna P, Cavallero C, Bosinelli M. Differential access to memory traces in the production of mental experience. Int J Psychophysiol. 1986;

101. Nielsen TA. A review of mentation in REM and NREM sleep: "Covert" REM sleep as a possible reconciliation of two opposing models. Behav Brain Sci. 2000;

102. Senkov O, Andjus P, Radenovic L, Soriano E, Dityatev A. Neural ECM molecules in synaptic plasticity, learning, and memory. Prog Brain Res. 2014;214(November):53-80.

103. Gogolla N, Caroni P, Lüthi A, Herry C. Perineuronal nets protect fear memories from erasure. Science (80- ). 2009;

104. Wright JW, Harding JW. Contributions of Matrix Metalloproteinases to Neural Plasticity, Habituation, Associative Learning and Drug Addiction. Neural Plast. 2009;

105. Wang X, Bozdagi O, Nikitczuk JS, Zhai ZW, Zhou Q, Huntley GW. Extracellular proteolysis by matrix metalloproteinase- 9 drives dendritic spine enlargement and long-term potentiation coordinately. Proc Natl Acad Sci U S A. 2008;

106. Vickers CA, Wyllie DJA. Late-phase, protein synthesis-dependent long-term potentiation in hippocampal CA1 pyramidal neurones with destabilized microtubule networks. Br J Pharmacol. 2007;151(7):1071-7.

107. Eom T, Antar LN, Singer RH, Bassell GJ. Localization of a beta-actin messenger ribonucleoprotein complex with zipcode-binding protein modulates the density of dendritic filopodia and filopodial synapses. J Neurosci. 2003;23(32):10433-44.

108. Klein ME, Younts TJ, Castillo PE, Jordan BA. RNA-binding protein Sam68 controls synapse number and local $\beta$-actin mRNA metabolism in dendrites. Proc Natl Acad Sci U S A. 2013;110(8):3125-30.

109. Rosenberg GA. Matrix metalloproteinases and their multiple roles in neurodegenerative diseases. Lancet Neurol. 2009;8(2):205-16.

110. Gonthier B, Nasarre C, Roth L, Perraut M, Thomasset N, Roussel G, et al. Functional interaction between matrix metalloproteinase-3 and semaphorin-3C during cortical axonal growth and guidance. Cereb Cortex. 2007;17(7):1712-21.

111. Van Hove I, Verslegers M, Buyens T, Delorme N, Lemmens K, Stroobants S, et 
al. An aberrant cerebellar development in mice lacking matrix metalloproteinase3. Mol Neurobiol. 2012;45(1):17-29.

112. Meighan SE, Meighan PC, Choudhury P, Davis CJ, Olson ML, Zornes PA, et al. Effects of extracellular matrix-degrading proteases matrix metalloproteinases 3 and 9 on spatial learning and synaptic plasticity. J Neurochem. 2006;96(5):122741.

113. Kim YS. Matrix Metalloproteinase-3: A Novel Signaling Proteinase from Apoptotic Neuronal Cells That Activates Microglia. J Neurosci [Internet]. 2005;25(14):3701-11. Available from: http://www.jneurosci.org/cgi/doi/10.1523/JNEUROSCI.4346-04.2005

114. Kim E-M, Hwang O. Role of matrix metalloproteinase-3 in neurodegeneration. J Neurochem [Internet]. 2011;116(1):22-32. Available from: http://doi.wiley.com/10.1111/j.1471-4159.2010.07082.x

115. Sung JY, Park SM, Lee CH, Um JW, Lee HJ, Kim J, et al. Proteolytic cleavage of extracellular secreted $\alpha$-synuclein via matrix metalloproteinases. J Biol Chem. 2005;280(26):25216-24.

116. Choi DH, Kim YJ, Kim YG, Joh TH, Beal MF, Kim YS. Role of matrix metalloproteinase 3-mediated ??-synuclein cleavage in dopaminergic cell death. J Biol Chem. 2011;286(16):14168-77.

117. Choi DH, Kim YJ, Kim YG, Joh TH, Beal MF, Kim YS. Role of matrix metalloproteinase 3-mediated ??-synuclein cleavage in dopaminergic cell death. J Biol Chem. 2011;286(16):14168-77.

118. Teismann P, Schulz JB. Cellular pathology of Parkinson's disease: Astrocytes, microglia and inflammation. Cell Tissue Res. 2004;318(1):149-61.

119. Annese V, Herrero MT, Di Pentima M, Gomez A, Lombardi L, Ros CM, et al. Metalloproteinase-9 contributes to inflammatory glia activation and nigro-striatal pathway degeneration in both mouse and monkey models of 1-methyl-4-phenyl1,2,3,6-tetrahydropyridine (MPTP)-induced Parkinsonism. Brain Struct Funct. 2015;220(2):703-27.

120. Lorenzl S, Calingasan N, Yang L, Albers DS, Shugama S, Gregorio J, et al. Matrix metalloproteinase-9 is elevated in 1-methyl-4-phenyl-1,2,3,6tetrahydropyridine-induced parkinsonism in mice. Neuromolecular Med. 2004;5(2):119-32.

121. Lorenzl S, Calingasan N, Yang L, Albers DS, Shugama S, Gregorio J, et al. Matrix metalloproteinase-9 is elevated in 1-methyl-4-phenyl-1,2,3,6tetrahydropyridine-induced parkinsonism in mice. Neuromolecular Med [Internet]. 2004;5(2):119-32. Available from: http://www.ncbi.nlm.nih.gov/pubmed/15075439

122. Agrawal SM, Lau L, Yong VW. MMPs in the central nervous system: Where the good guys go bad. Semin Cell Dev Biol. 2008;19(1):42-51. 
123. Paxinos G, Watson C. The Rat Brain in Stereotaxic Coordinates Sixth Edition by. Acad Press. 2006;170:547612.

124. Jackson-Lewis V, Blesa J, Przedborski S. Animal models of Parkinson's disease. Parkinsonism Relat Disord [Internet]. 2012;18(October):S183-5. Available from: http://dx.doi.org/10.1016/S1353-8020(11)70057-8

125. Heikkila RE, Nicklas WJ, Vyas I, Duvoisin RC. Dopaminergic toxicity of rotenone and the 1-methyl-4-phenylpyridinium ion after their stereotaxic administration to rats: Implication for the mechanism of 1-methyl-4-phenyl1,2,3,6-tetrahydropyridine toxicity. Neurosci Lett. 1985;62(3):389-94.

126. Betarbet R, Sherer TB, Mackenzie G, Garcia-osuna M, Panov A V, Greenamyre JT. Chronic systemic pesticide exposure reproduces features of Parkinson's disease. Nat Neurosci. 2000;3(12):1301-6.

127. Zhang ZN, Zhang JS, Xiang J, Yu ZH, Zhang W, Cai M, et al. Subcutaneous rotenone rat model of Parkinson's disease: Dose exploration study. Brain Res. 2017;1655:104-13.

128. Greenamyre JT, Betarbet R, Sherer TB. The rotenone model of Parkinson's disease: genes, environment and mitochondria. Parkinsonism Relat Disord. 2003;9:59-64.

129. Cohen HB, Dement WC. Sleep: changes in threshold to electroconvulsive shock in rats after deprivation of "paradoxical" phase. Science (80- ) [Internet]. 1965;150(3701):1318-9. Available from:

http://www.ncbi.nlm.nih.gov/entrez/query.fcgi?cmd=Retrieve \&db=PubMed\&do $\mathrm{pt}=$ Citation\&list_uids $=5857002$

130. Machado RB, Hipólide DC, Benedito-Silva AA, Tufik S. Sleep deprivation induced by the modified multiple platform technique: Quantification of sleep loss and recovery. Brain Res. 2004;1004(1-2):45-51.

131. Pfaffl MW. A new mathematical model for relative quantification in. 2001;29(9):16-21. 